\title{
GESTIÓN Y VALORACIÓN DEL PATRIMONIO HISTÓRICO INMUEBLE EN EL CENTRO HISTÓRICO DEL CALLAO ${ }^{(*)}$
}

\author{
MANAGEMENT AND ASSESSMENT OF THE BUILT HERITAGE \\ IN THE HISTORIC CENTRE OF CALLAO \\ MARSIA MONTAÑEZ ARICA ${ }^{[\star]}$ \\ Fecha de recepción: 30 de agosto de 2016 \\ Fecha de aprobación: 26 de noviembre de 2016
}

\section{RESUMEN}

Un centro histórico identifica culturalmente a su comunidad. Su conservación no puede aislarse de su contexto físico y social, ni puede separarse de las actividades de desarrollo de la ciudad, de manera que son importantes las acciones colaborativas y la participación de todos los actores sociales involucrados. Su complejidad requiere que se empleen enfoques adecuados de gestión. En el Centro Histórico del Callao (Perú), donde el patrimonio inmueble se encuentra en situación precaria, abandonado o derruido, existe una problemática en torno a su conservación. Por esta razón, en el presente artículo se estudia la relación entre su estado de conservación en 2015, y los instrumentos de gestión y de valoración del patrimonio. El análisis revela la carencia de procesos de reconocimiento y de protección del patrimonio inmueble que complementen los dispositivos legales existentes; asimismo, evidencia la falta de coordinación y colaboración entre los organismos públicos encargados de resguardarlo.

\section{PALABRAS CLAVE}

Centro histórico del Callao, valores patrimoniales, gestión del patrimonio histórico inmueble

\section{ABSTRACT}

A historic centre has an important meaning for the local community. Its preservation cannot be isolated from its physical and social context nor ignore the city's urban development. Therefore, collaborative actions and the participation of all social stakeholders involved are crucial. This complex situation requires suitable management approaches. In regard to the Historic Centre of Callao (Peru), where the built heritage is in a precarious situation, abandoned or demolished, there are issues concerning its preservation. This paper examines the relationship between its state of preservation in 2015 , and management processes and tools that help identify heritage values. The analysis shows there is a lack of cultural heritage identification and protection processes that complement existing legal provisions. It also demonstrates the poor coordination and communication between the public dependencies in charge of built heritage.

\section{KEYWORDS}

Historic Centre of Callao, heritage values, built heritage management

(*) Este artículo se desarrolló a partir de la investigación titulada Diagnóstico del estado actual y pautas para la valoración del Centro Histórico del Callao y su patrimonio histórico inmueble, realizada en el Taller de Investigación en Historia de la Arquitectura en los años 2013 y 2016, bajo la responsabilidad del MSc Arq. José Beingolea Del Carpio, y luego del MSc Arq. Carlos Guzmán García y el MSc Arq. José Hayakawa Casas, en el marco académico de la Facultad de Arquitectura, Urbanismo y Artes de la Universidad Nacional de Ingeniería (UNI).

(**) Bachiller en Arquitectura por la UNI. Profesionalmente ha formado parte del equipo del Programa de Conservación de Casonas del distrito de Miraflores. Actualmente desarrolla el proyecto de tesis de grado con la propuesta de un equipamiento cultural en el centro histórico del Callao. Contacto: marsia.lorena@gmail.com 


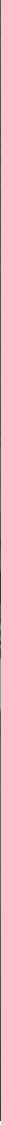

La mayor parte del territorio nacional alberga bienes inmuebles declarados 'patrimonio cultural' 'que, en líneas generales, se encuentran en estado de abandono, olvidados en el tiempo y sin aparente posible recuperación. Así, pues, existe una problemática en torno a su conservación.

A partir de la década de 1960, en el ámbito internacional, la salvaguarda del patrimonio pasa de la ocuparse de la edificación aislada a considerar el conjunto ${ }^{2}$. El conjunto urbano más importante y complejo es el centro histórico de una ciudad, debido a que lo caracteriza "la alta concentración de valores simbólicos relacionados al concepto de identidad, conviviendo con elevados índices de pobreza, marginalidad y deterioro social y edilicio" (Rodríguez, 2008, p. 54).

Muestra de su importancia es que, en el Perú, el Centro Histórico de Lima, la Ciudad del Cusco y el Centro Histórico de la Ciudad de Arequipa estén incluidos en la Lista del Patrimonio Mundial.

\footnotetext{
1. De las 25 circunscripciones regionales del Perú (24 departamentos y una provincia constitucional), 22 po seen por lo menos un monumento declarado Patrimonio Cultural de la Nación. Los únicos departamentos que no registran patrimonio histórico inmueble son Madre de Dios, San Martín y Ucayali (Valenzuela, 2015).

2. La Carta de Venecia de 1964 plantea que el monumento histórico comprende tanto la obra arquitectónica aislada como el conjunto urbano o rural. El problema de la preservación del conjunto histórico también fue discutido en el Congreso de la Federación Internacional de Vivienda y Urbanismo celebrado en Santiago de Compostela en 1961, y en las Normas de Quito en 1967 (Rodríguez 2008).
}

Figura 1. Vista del centro histórico y el puerto del Callao desde el interior de un monumento en Jr. Independencia Fuente: Archivo fotográfico Marsia Montañez, 2013. 
Dados estos antecedentes, se elige como objeto de estudio al Centro Histórico del Callao, el cual, a pesar de encontrarse ubicado dentro de la conurbación formada por la capital del país, presenta un avanzado deterioro (Figura 1). Por lo tanto, se pretende analizar la gestión del patrimonio y la valoración del patrimonio histórico inmueble comprendido en dicha área.

El objetivo de esta investigación implica difundir información sobre el valor del Centro Histórico del Callao y su patrimonio histórico inmueble, pero, principalmente, conocer y analizar tanto los procesos de reconocimiento de los valores patrimoniales como los instrumentos de gestión empleados para la protección del mismo, con la finalidad de identificar la influencia que ejercen en su estado de conservación.

Para ello, se estudia una muestra de las edificaciones y los espacios urbanos que forman parte del centro histórico, y se emplea una metodología de carácter cuantitativo a través de la recolección de datos de documentación histórica y teórica, así como mediante la observación de campo llevada a cabo con el uso de fichas.

Una limitación importante del estudio es que, desde fines de 2015, este centro histórico atraviesa un importante proceso de cambio en su dinámica social y en su apariencia. Debido a que tal proceso ha sido posterior al período en el que se recabaron los datos, esta variación no se incluye en el análisis.

\section{Conceptos}

En primer lugar,'patrimonio histórico inmueble' es una categoría establecida por el Ministerio de Cultura que corresponde a bienes culturales inmuebles virreinales o republicanos. Comprende monumentos, ambientes urbanos monumentales y zonas monumentales.

Por otro lado,'valor patrimonial' se define como la 'cualidad que poseen [...los] bienes, por lo cual son estimables'. Este tipo de estimación puede ser de diferente índole o magnitud según variables de análisis diversas" (Hayakawa, 2015, p. 40).

Según Zuleta y Jaramillo (2003), en el análisis económico, el valor de los bienes y servicios en los mercados es determinado por los consumidores. Análogamente, el valor de un bien patrimonial estaría determinado por las decisiones de los ciudadanos.

Para Ballart, Fullola y Petit (1996), la idea de un bien cultural sugiere encontrarse ante algo de valor. Este valor sería el de "aprecio hacia determinados objetos por el mérito que atesoran, por la utilidad que manifiestan, o por su aptitud para satisfacer necesidades o proporcionar bienestar. Por todo eso el valor no es siempre inherente a las cosas" (como se citó en Hayakawa, 2015, p. 40).

En el ámbito de la economía, la valuación se basa "en la preferencia de los consumidores y no en las opiniones de los expertos" (Zuleta \& Jaramillo, 2003, p. 19). De manera semejante,

....el valor efectivo de determinados objetos del pasado para la sociedad o para los distintos grupos de la sociedad, sólo puede establecerse en función de determinados contextos. [...] El potencial de los bienes históricos como recurso ha de ser evaluado en cualquier caso a la luz de contextos específicos, ya que la atribución de valor sólo puede existir en función de situaciones reales y socialmente determinadas (Ballart et al., 1996, p. 216)

Para clasificar los valores patrimoniales, Ballart et al. (1996) distinguen entre tres valores:

- Valor de uso: Entendido como uso para algo; "para satisfacer una necesidad material, un deseo de conocimiento o un interés mundano" (p. 216). Puede tratarse de uso directo o indirecto (Zuleta \& Jaramillo, 2003): en el primer caso, está relacionado al uso actual de los bienes; en el 


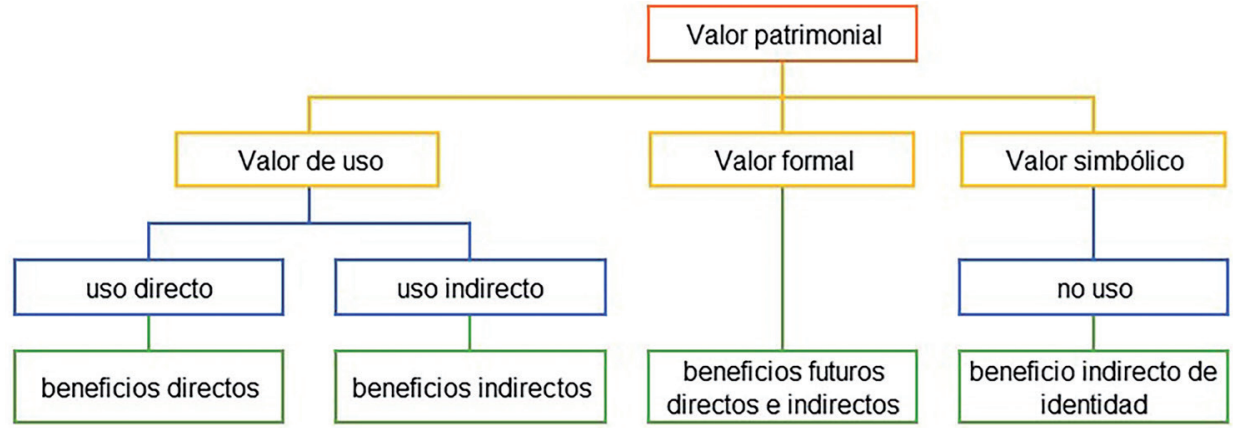

Decrece la "tangibilidad" del valor para individuos segundo, a los beneficios indirectos derivados de ellos, tales como oportunidades de negocios, empleo, incremento del conocimiento, entre otros.

- Valor formal: Estimación de ciertos bienes “por la atracción que despiertan en las personas por razón de su forma y por las cualidades inherentes que presentan" (Ballart et al., 1996, p. 216)

- Valor simbólico o comunicativo: “Consideración en que se tiene a determinados [bienes] en tanto que son sustitutos de algo que no existe, es decir, de algo del pasado y no del presente, sea ésto [sic] una persona, una historia, un hecho o una idea" (p. 216)

En relación con lo anterior, se establece una analogía entre estas categorías y los valores económicos definidos por Ismail Serageldin, vicepresidente del Banco Mundial entre 1992 y 2000 (Figura 2).

Según Ballart et al. (1996), a estas tres categorías se puede adjudicar diversos subvalores. Por lo tanto, al no existir una relación de valores que poseen los bienes culturales, se propone aquí una clasificación de valores patrimoniales (Tabla 1).

Por último, la 'gestión del patrimonio cultural' se compone de procesos que ayudan a conservar un determinado bien o grupo de bienes culturales, de modo que se protejan sus valores patrimoniales y se promueva la obtención de beneficios sociales, económicos y ambientales. Su objetivo consiste en garantizar la protección o el mantenimiento del bien cultural a largo plazo. El enfoque de la gestión del patrimonio puede ser i) "convencional” o ii) "basado en valores" (UNESCO, 2014, pp. 25-27).

En síntesis, la sociedad atribuye un valor al bien como una interpretación de su carácter particular y según el interés subjetivo que tiene en este; de esta manera, el bien adquiere una cualidad cultural. Por su parte, los expertos establecen los criterios para identificar estos valores, los cuales determinarán la base para elaborar las estrategias necesarias para su gestión.

\section{Contexto del Centro Histórico del Callao}

La Provincia Constitucional del Callao se ubica en la costa central del Perú. Limita al Norte, Este y Sur con la provincia de Lima -con la cual forma la conurbación más extensa del país conocida como Lima Metropolitana-. Dentro de su territorio se sitúa el centro histórico, al sudoeste del distrito del Callao, detrás del terminal portuario homónimo (Figura 3).

El centro histórico se conecta al resto de la provincia por los ejes viales i) Manco Cápac, ii) 2 de Mayo y iii) Sáenz Peña. Al Oeste, la Av. Manco Cápac separa el centro histórico
Figura 2. Mapa conceptual de categorías de los valores patrimoniales y sus beneficios

Fuente: Elaboración propia sobre la base de "Categoría de valores económicos atribuidos a los activos de la herencia cultural" [Gráfico], en Zuleta \& Jaramillo, 2003, p. 22 
devenir Vol. 3, Nº6, JULIO-DICIEMBRE 2016, PP. 98-124 - EstudIOS I ISSN 2312-7570

UNIVERSIDAD NACIONAL DE INGENIERÍA, LIMA

Tabla 1. Subclasificación de valores patrimoniales para el bien inmueble

\begin{tabular}{|c|c|}
\hline Valor patrimonial & Descripción \\
\hline \multicolumn{2}{|l|}{ De uso } \\
\hline Económico & Generado por el bien cultural o por la acción de conservación. ${ }^{1}$ \\
\hline Funcional & $\begin{array}{l}\text { Relacionado con el valor económico, en tanto involucra la conti- } \\
\text { nuidad de la clase original de función o a la iniciación de un uso } \\
\text { compatible. }\end{array}$ \\
\hline Educativo & $\begin{array}{l}\text { Basado en los beneficios que genera el patrimonio en términos de } \\
\text { educación. }{ }^{2} \text { El bien posee potencial para el turismo cultural, y la } \\
\text { concientización sobre la cultura y la historia. }^{1}\end{array}$ \\
\hline Social & $\begin{array}{l}\text { El bien patrimonial incluye la interacción social en la comunidad, } \\
\text { y tiene un rol importante en el establecimiento de la identidad } \\
\text { social y cultural. }{ }^{1}\end{array}$ \\
\hline Científico & $\begin{array}{l}\text { Basado en el examen detenido que sobre el propio bien cultural } \\
\text { puede hacerse. De este examen resulta una información que contri- } \\
\text { buye a incrementar el conocimiento humano. }{ }^{3}\end{array}$ \\
\hline
\end{tabular}

Formal

Técnico o artístico

Basado en la investigación. Se sustenta en evaluaciones científicas e histórico-críticas, así como en la determinación de la importancia del diseño del bien cultural, y la relevancia de su concepción y hechura en términos técnicos, estructurales y funcionales.

Basado en estadísticas. Define la originalidad del bien, su repre-

De originalidad sentatividad o singularidad en relación con otras construcciones del mismo tipo, estilo, constructor, periodo, región, o el conjunto de estos.

De conjunto

Basado en su unidad o armonía total, e integración al paisaje.

\section{Simbólico o comunicativo}

Histórico

De existencia

De legado

De identidad

De imagen
Basado en el análisis, apoyado en el estudio de las fuentes documentales. El bien patrimonial es un testigo único de determinado suceso. Este valor permite a una comunidad referenciar el bien cultural en un momento determinado de la historia.

Equivale al goce de la simple existencia del bien cultural para una comunidad o persona, independientemente si haga uso o no de él. ${ }^{2}$

Valor que las generaciones futuras adquieren del bien cultural. ${ }^{2}$

Basado en el reconocimiento. Relacionado con los lazos emocionales de la sociedad hacia bienes culturales específicos. Pueden incluir características como edad, tradición, continuidad, conmemoración y leyenda; o vínculos sentimentales, espirituales o religiosos. ${ }^{1}$

Posibilidad de conocer a través del bien cultural las razones que dieron lugar a la evolución histórica, cambios significativos y, por tanto, a la configuración de una imagen específica. ${ }^{3}$

Nota: Elaboración propia sobre la base de Hayakawa (2015) y Ballart et al. (1996), 2016.

${ }^{1}$ Jokilehto \& Feilden (como se citó en Hayakawa, 2015, p. 74).

${ }^{2}$ Traducción propia de Frey y Pommerehne (como se citó en Hayakawa, 2015, p. 41).

${ }^{3}$ Ballart et al., 1996. 

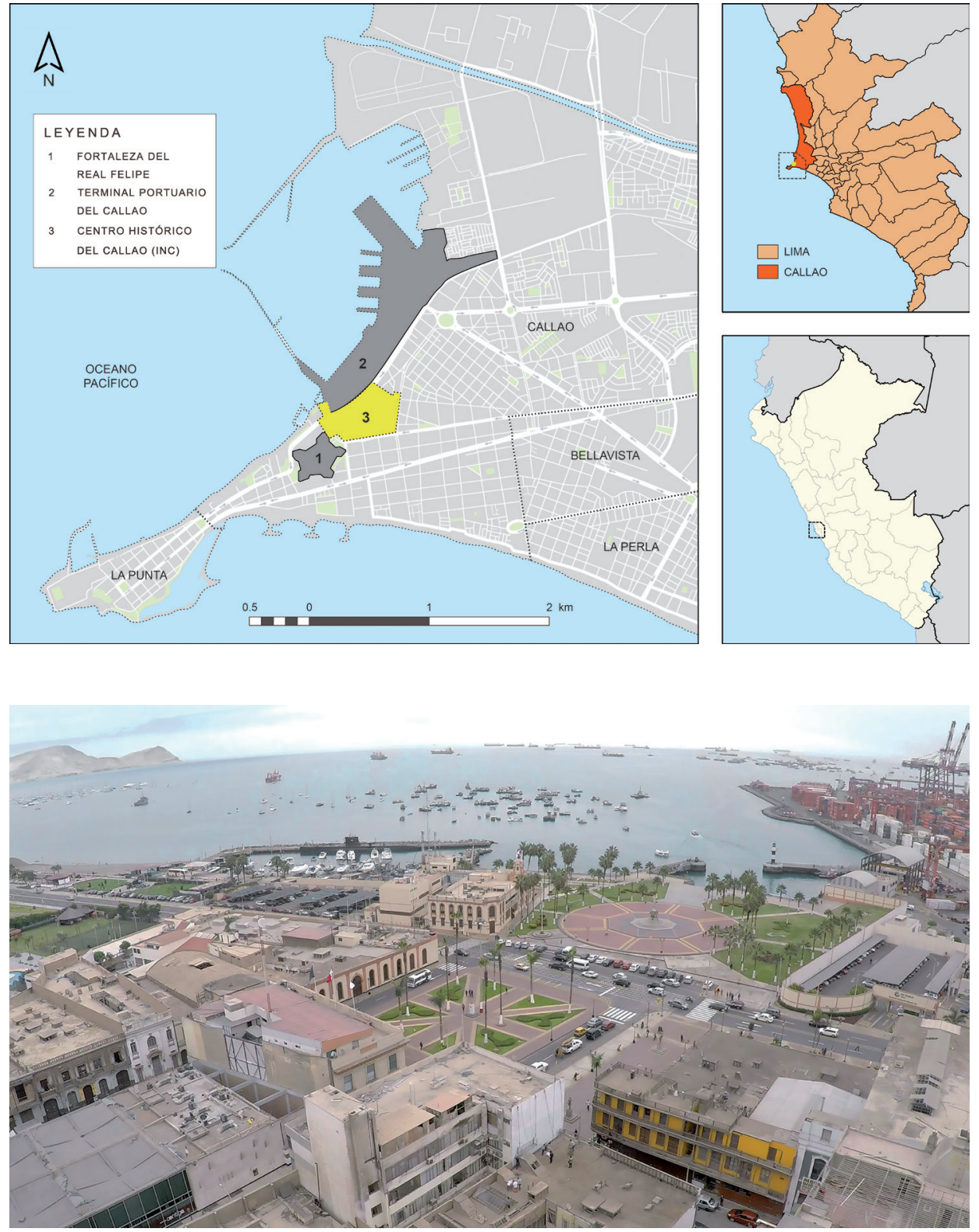

del terminal portuario; al Este, la Av. 2 de Mayo es el resultado del ensanche del Jr. Piura a principios de la década de 1950; y al sur, la Av. Sáenz Peña es el eje tradicional de la actividad comercial. Su principal conexión con la ciudad de Lima es a través de la Av. Óscar R. Benavides, por donde circula el transporte público interurbano.

\section{Geografía}

El centro histórico se asienta en la bahía del Callao -de suelo llano y suave pendiente hacia el mar-, a una altitud que varía entre los 3 y 10 m.s.n.m. (Figura 4). El clima es subtropical desértico: presenta lloviznas de larga duración, pero poca intensidad; vientos dominantes provenientes del Sur y Noroeste, con velocidades de 2 a $4 \mathrm{~m} / \mathrm{s}$; una temperatura del aire promedio anual que oscila entre $17,8^{\circ} \mathrm{C}$ y $19,2^{\circ} \mathrm{C}$; y una humedad relativa promedio anual de 88 a $90 \%$, con presencia de neblina durante gran parte
Figura 3. Ubicación del Centro Histórico del Callao (según el Instituto Nacional de Cultura, 2010)

Fuente: Adaptación propia a partir de Huhsunqu, 2009; y AgainErick, 2008, 2016.

Figura 4. Vista panorámica de la bahía del Callao, 2015

Fuente: Flores, 2015. 

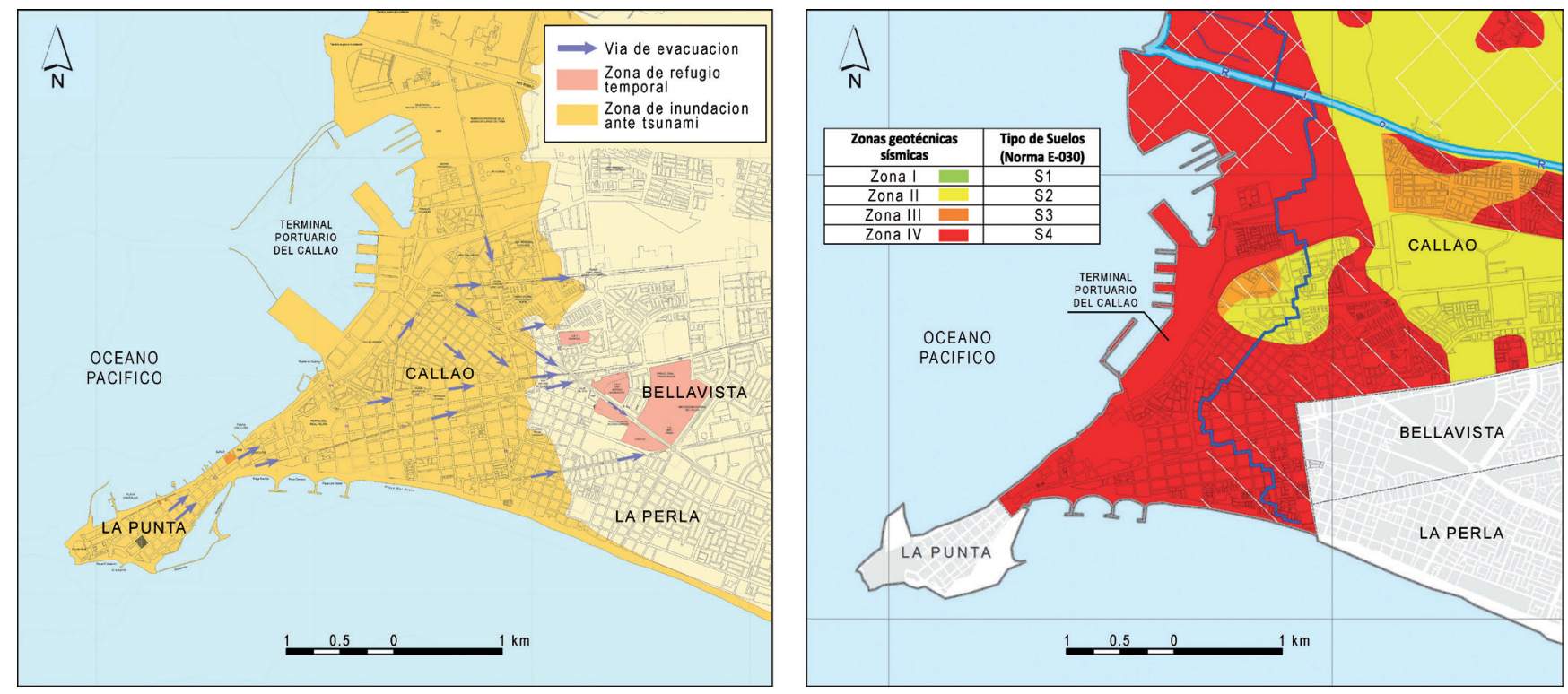

Figura 5. Mapa de inundación y de zonificación sísmica-geotectónica para el Centro Histórico del Callao

Fuente: Adaptado de INDECI, 2010; y Dirección de Hidrografía y Navegación, 2011, 2016. del año (Municipalidad Provincial del Callao, 2010, pp. 103-104; Instituto Nacional de Estadística e Informática [INEI], 2015, p. 51).

Según la "Norma Técnica E.030" del Reglamento Nacional de Edificaciones, pertenece a la Zona 4 de acuerdo a su zonificación geotécnica sísmica, considerada la más desfavorable por el muy alto peligro sísmico que representa para las edificaciones (Instituto Nacional de Defensa Civil [INDECI], 2010). Análogamente, aunque su costa presenta frecuentemente un oleaje reducido, el lugar enfrenta un alto riesgo de inundación por tsunami (Municipalidad Provincial del Callao, 2010, p. 141). Las vías de evacuación para la zona monumental son las avenidas Sáenz Peña, con dirección este, y 2 de Mayo, con dirección norte (Figura 5).

\section{Población}

Según los resultados expuestos por el INEI (2007) en el Censo Nacional de Población y de Vivienda, el distrito del Callao era el más poblado de la provincia con 415,888 habitantes y una densidad poblacional de 9,110 hab./km² (Figura 6).

Las proyecciones de población del INEI muestran que para 2015 había 406,889 habitantes -el 50,1\% eran hombres, y el 49,9\%, mujeres-, lo que representaba una disminución de 2,16\%: el distrito del Callao tiene una tasa de crecimiento baja con una tendencia decreciente desde el censo de 1940. Por otra parte, entre los años 2002 y 2007 , la tasa neta de migración interna para la población de 5 y más años de edad era de $-6,1$ por cada mil habitantes; es decir, había más población migrante hacia otros distritos de Lima Metropolitana y del país.

Asimismo, la distribución de la población ${ }^{3}$ mostraba una tendencia hacia el envejecimiento: el 68,5\% correspondía a la población adulta y el índice de envejecimiento era de 26,4 adultos mayores por cada 100 jóvenes. Por cada 100 personas adultas -o en edad de trabajar- había 46 personas económicamente dependientes, de los cuales 36 eran jóvenes y 10 , adultos mayores.

3. Población clasificada en tres grandes grupos de edad: de 0 a 14 años, de 15 a 64 años, y de 65 años y más; esto es, jóvenes, adultos y adultos mayores. 


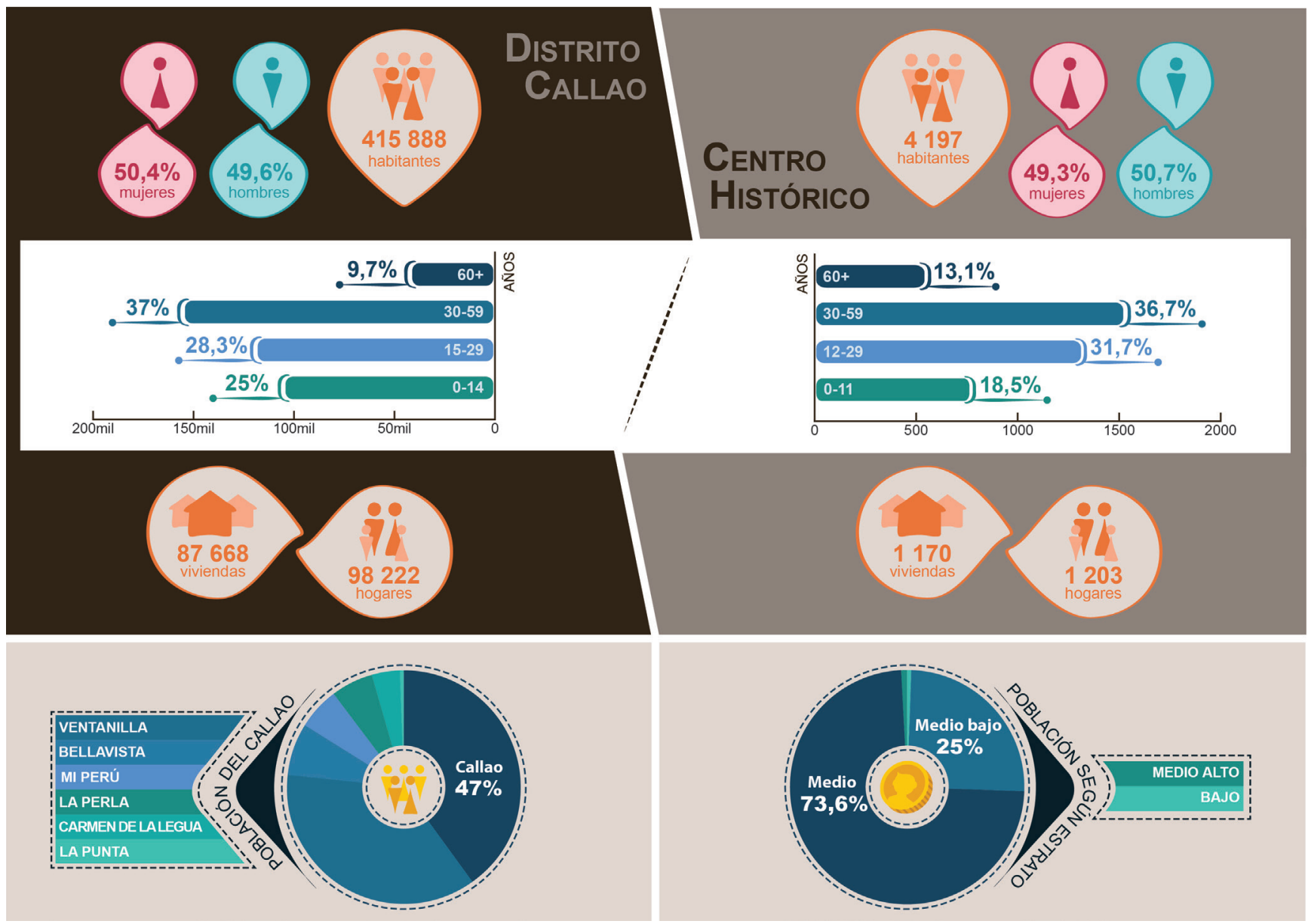

En el distrito, las viviendas particulares que albergaban un hogar representaban el $91 \%$; dos hogares, $6.6 \%$; tres hogares, $1.9 \%$; y cuatro o más hogares, $0.5 \%$. De los 98,222 hogares censados, los conformados por tres o cuatro miembros correspondían al 41.8\%; por cinco o más miembros, 36.9\%; por dos miembros, $12.7 \%$; y los hogares unipersonales, $8.6 \%$.

Por otro lado, la población en edad de trabajar (PET) - de 14 y más años- del distrito era de 319,471 habitantes $(76.8 \%$ del total), mientras que la población económicamente activa (PEA) era de 176,640 habitantes (69.9\% hombres y $41.2 \%$ mujeres), lo que denotaba una tasa de actividad de 55.3\%. La PEA ocupada constituía el $95.5 \%$ y la desocupada indicaba una tasa de desempleo de 4.5.

De acuerdo al nivel educativo alcanzado, el $13.7 \%$ de la PET tenía por lo menos el nivel primaria (incluido el $2.3 \%$ sin nivel de educación); el $44.0 \%$, nivel secundaria; y el $42.3 \%$ contaba con educación superior. La tasa de analfabetismo alcanzaba el 1.6\%.

En paralelo, la población del Centro Histórico del Callao era de 4,197 habitantes, distribuida en 38 de 47 manzanas, de las cuales el 50\% estaban ocupadas por entre 1 y 100 personas. El $58.1 \%$ correspondía a la población adulta (de 18 a 59 años), y el índice de envejecimiento era de 45.3 adultos mayores (60+ años) por cada 100 jóvenes (menores de 18 años).
Figura 6. Comparación de datos estadísticos de la población del distrito del Callao y la del centro histórico, 2007

Fuente: Montañez, 2016. 
En promedio, cada vivienda albergaba 1 hogar, y cada hogar estaba conformado por 3.5 miembros. El estrato socioeconómico predominante de la población era medio; es decir, percibía un ingreso per cápita mensual de entre 482 y 672 nuevos soles (Figura 6).

Finalmente, el centro histórico tenía una densidad residencial ${ }^{4}$ baja, con 25,9 viv./ha., menor a la requerida para asegurar un mínimo de vitalidad urbana (Vicuña del Río, 2013, Introducción).

\section{Historia}

Es escasa la documentación sobre la historia del Callao en relación a sus primeros tiempos de existencia. El puerto nació sin acta de fundación; su historia como ciudad virreinal se inició en 1537 con el establecimiento del primer edificio, un tambo bodega (Quiroz, 2007).

Al inicio, se trató de una población anexa a la Ciudad de los Reyes ${ }^{5}$, sin una denominación oficial. Originalmente, Pizarro le dio al puerto el nombre de Santa Marina; posteriormente, fue llamado Puerto de la Ciudad de los Reyes, el Pedregal, el Cascajal o el Callao de Lima. A inicios del siglo XVII, recibió la denominación 'Callao' según un documento de 1616 escrito por el cronista Martín de Murúa (Quiroz, 2007).

La trama urbana primitiva, de conformación reticular, fue protegida por una muralla hasta la desaparición de ambas como consecuencia del terremoto y maremoto ocurridos en octubre de 1746. A pesar de ello, la población reocupó de forma espontánea -sin un planteamiento urbano previo- y temporal las antiguas áreas del puerto, lo que dio como resultado un trazo irregular y calles de sección estrecha: "toda fábrica que se permite por el gobierno es con la condición de echarlas por tierra y demolerlas a costas de sus dueños" (Giannuzzi \& Williams, 1983). Según Quiroz (2007), la historia de su arquitectura después de 1746 puede ser descrita en tres diferentes etapas: i) chozas o reinicio, ii) republicana, $y$ iii) siglos XX y XXI.

Actualmente, al sudeste del distrito del Callao existen zonas diferenciadas por su morfología, lo que manifiesta una estructura urbana heterogénea a consecuencia de los diversos momentos de su conformación. Este proceso de ocupación se generó desde el núcleo original -actual centro histórico- hacia el Este (Lima) y, luego, hacia el Norte (Ventanilla; Municipalidad Provincial del Callao, 2010).

Durante los últimos años, la provincia ha continuado extendiéndose de forma improvisada hasta conformar la conurbación con la provincia de Lima, lo cual ha producido la total urbanización de su territorio.

En suma, es posible condensar la historia del Callao, antes y después de la República, en 11 etapas (Quiroz, 2007; Municipalidad Provincial del Callao, 2010):

\section{Antes de la República}

Callao hispánico (1537-1595): Papel importante en el comercio marítimo. Luego de los ataques de los primeros corsarios, el cabildo limeño asumió el control del puerto.

Período de transición (1596-1647): Importancia comercial y militar como puerto. Coexistencia de dos poderes gubernamentales: el cabildo limeño representaba los intereses locales; y el gobierno virreinal, los de la Corona de España. Culmina con la construcción de la muralla perimetral para contrarrestar el ataque de los piratas.

\footnotetext{
4. Definida como viviendas por hectárea. Se considera densidad baja de 10 a 30 viv./ha; densidad media, de 31 a 60 viv./ha; y densidad alta, de 61 a 90 viv./ha. (Pombo \& Camacho, 2010)

5. Nombre de la ciudad de Lima durante la época virreinal

6. La palabra 'chalaco', que significa pescador de la costa, ha sido establecida como su gentilicio.
} 


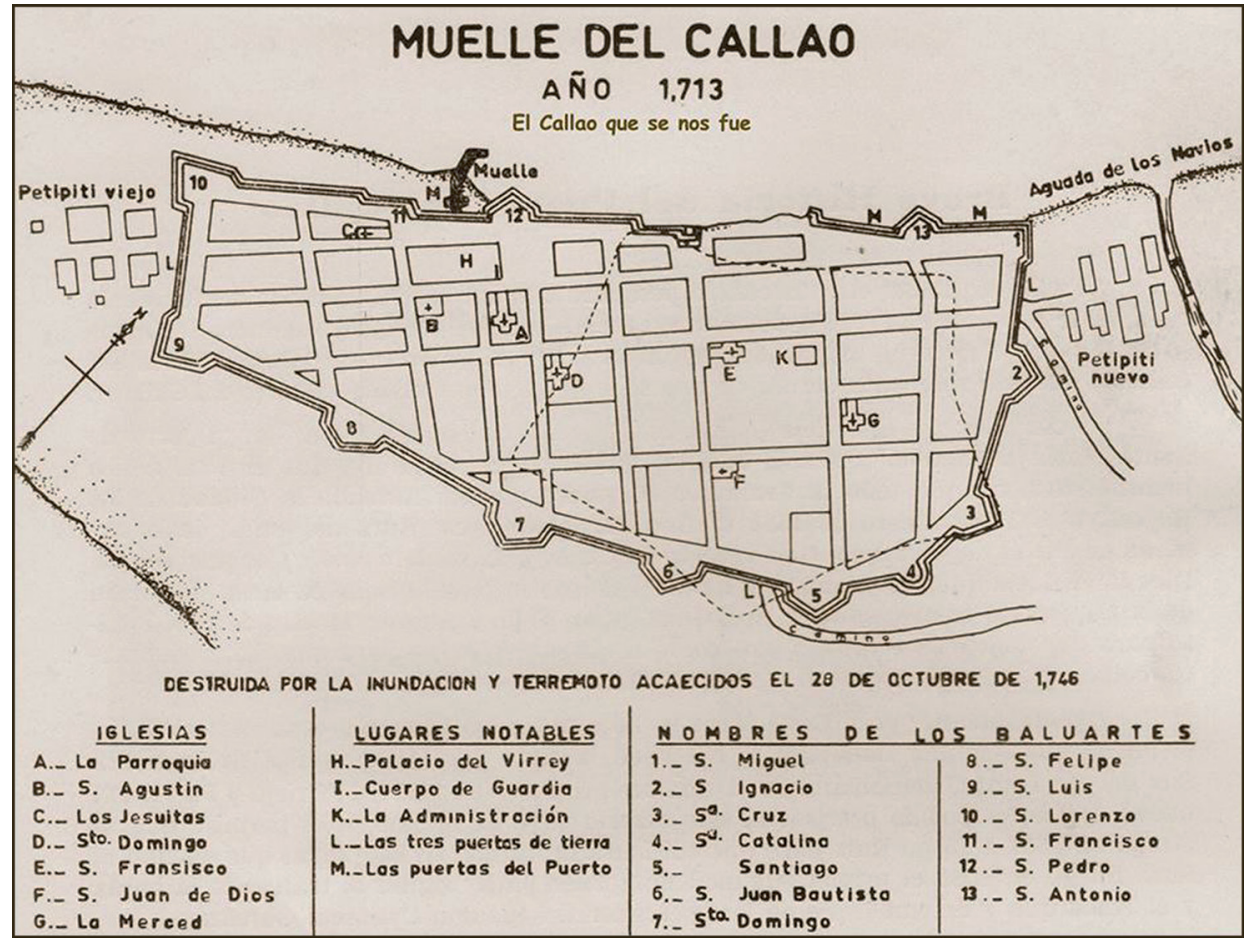

Figura 7. La ciudad amurallada y el muelle del Callao, 1713

Fuente: Gonzáles, 2016.

Figura 8. Reaparición de la ciudad del Callao y construcción de la Fortaleza del Real Felipe luego del terremoto de 1746 (1790)

Fuente: Adaptación propia de Plano de la Plaza, Fuertes, y Población del CaIlao, hacia 1790 [Plano], 2014.

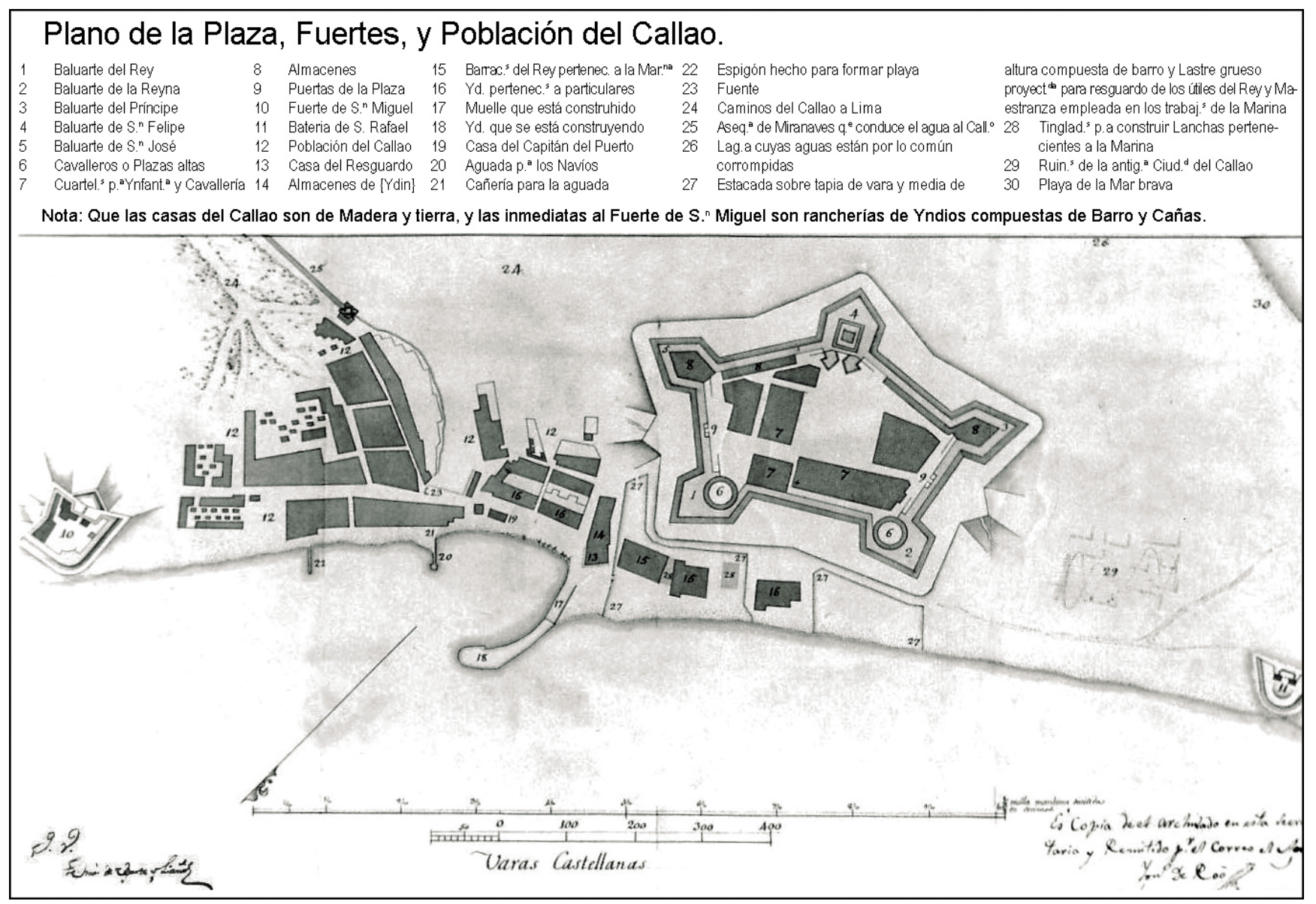


Callao amurallado (1648-1746; Figura 7): Predominio de los chalacos en el manejo del puerto. Culmina con la desaparición física de la ciudad en 1746 y la pérdida de la categoría de ciudad otorgada en 1671 por el Conde de Lemos.

Reconstrucción del puerto (1747-1805): Reconstrucción como fortaleza y desembarcadero de tránsito. Construcción de la Fortaleza del Real Felipe hasta 1774 y fundación de la nueva ciudad en Bellavista (alejada del mar para evitar futuros desastres naturales). Tras la división de las funciones estratégicas y comerciales, el puerto es manejado por las autoridades militares del Real Felipe. Reaparición de la ciudad del Callao; el cabildo limeño intenta anularlo y sustituirlo por Bellavista sin éxito (Figura 8).

Callao republicano (1806-1857): Inicio de acciones para la independencia del Perú. El puerto continúa bajo control militar; Bellavista es incorporada a este en 1821. Consolidación de la autonomía política y administrativa de la ciudad con la creación de la Provincia Litoral del Callao en 1836 -que la separó del departamento de Lima- y su declaración como Provincia Constitucional en 1857. En 1851, el ferrocarril inglés une Lima y Callao (Figura 9).

\section{Después de la República}

Primer período (1858-1940): Ocupación del espacio físico constituido por el puerto y la ciudad antigua anexa; culminación de la construcción del muelle y dársena del Callao en 1875; aparición de La Perla y las primeras áreas marginales en la periferia de la ciudad antigua; desarrollo de actividades comerciales e industriales a lo largo de la calle Lima, cuyo nombre cambia a Av. Sáenz Peña después de 1914; y desaparición del ferrocarril inglés en 1930 (Figura 10)

Segundo período (1940-1954): Consolidación de la actividad residencial en La Punta y la periferia de la ciudad antigua, aparición de grandes áreas marginales como consecuencia del terremoto de 1940 y el crecimiento urbano impulsado por el proceso de industrialización, aparición de las primeras áreas tugurizadas en la ciudad antigua, consolidación de la actividad comercial en la Av. Sáenz Peña y desarrollo de la actividad institucional en las inmediaciones de la fortaleza

Tercer período (1955-1969): Consolidación de las áreas urbanas aledañas a la ciudad antigua e incremento de las áreas tugurizadas, consolidación de las áreas marginales del período anterior, expansión del espacio físico de la provincia hacia el Norte con la anexión del distrito de Ventanilla, consolidación del Centro Comercial del Callao con la Av. Sáenz Peña como eje principal y construcción del Aeropuerto Internacional Jorge Chávez en la margen derecha del río Rímac

Cuarto período (1970-1984; Figura 11): Consolidación de la actividad residencial en los distritos de Bellavista, La Perla y Carmen de La Legua-Reynoso; crecimiento poblacional en La Punta; ocupación residencial incipiente en la zona este del aeropuerto; y desborde de la actividad comercial de la Av. Sáenz Peña, que se extendió hacia las vías Miguel Grau, 2 de Mayo y Moctezuma

Quinto período (1985-1994): Proliferación de asentamientos humanos en los alrededores del aeropuerto, crecimiento poblacional del distrito de Ventanilla y ampliación del distrito de La Perla

Sexto período (desde 1995): Crecimiento poblacional al norte del distrito del Callao, desborde del distrito de Ventanilla y creación del distrito Mi Perú

\section{Significación}

En la actualidad, el carácter de la Provincia Constitucional del Callao está vinculado a sus actividades económicas: industrias manufactureras, transporte y almacenamiento, 


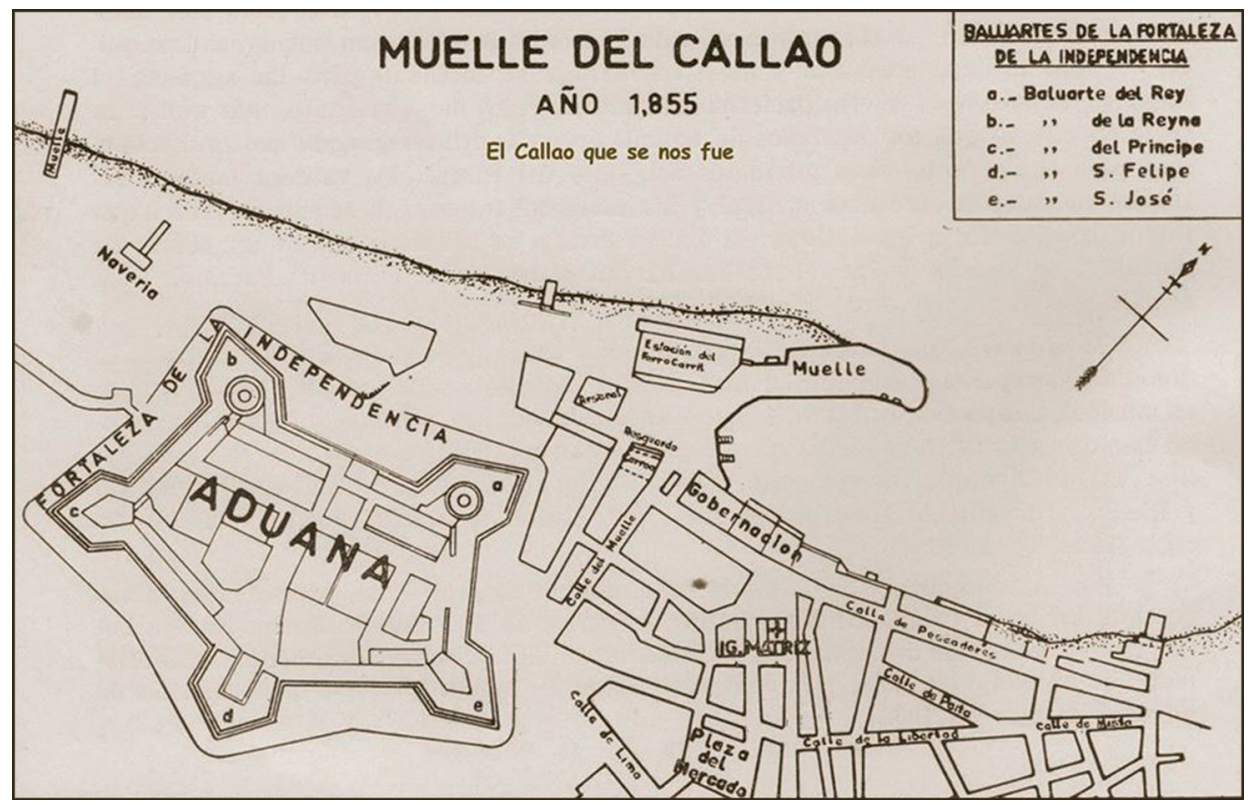

Figura 9. La ciudad, la estación del ferrocarril y el puerto del Callao a inicios de la República, 1855

Fuente: Gonzáles, 2016.

Figura 10. La ciudad del Callao, Bellavista y La Punta, 1900

Fuente: Gonzalinux, 2012

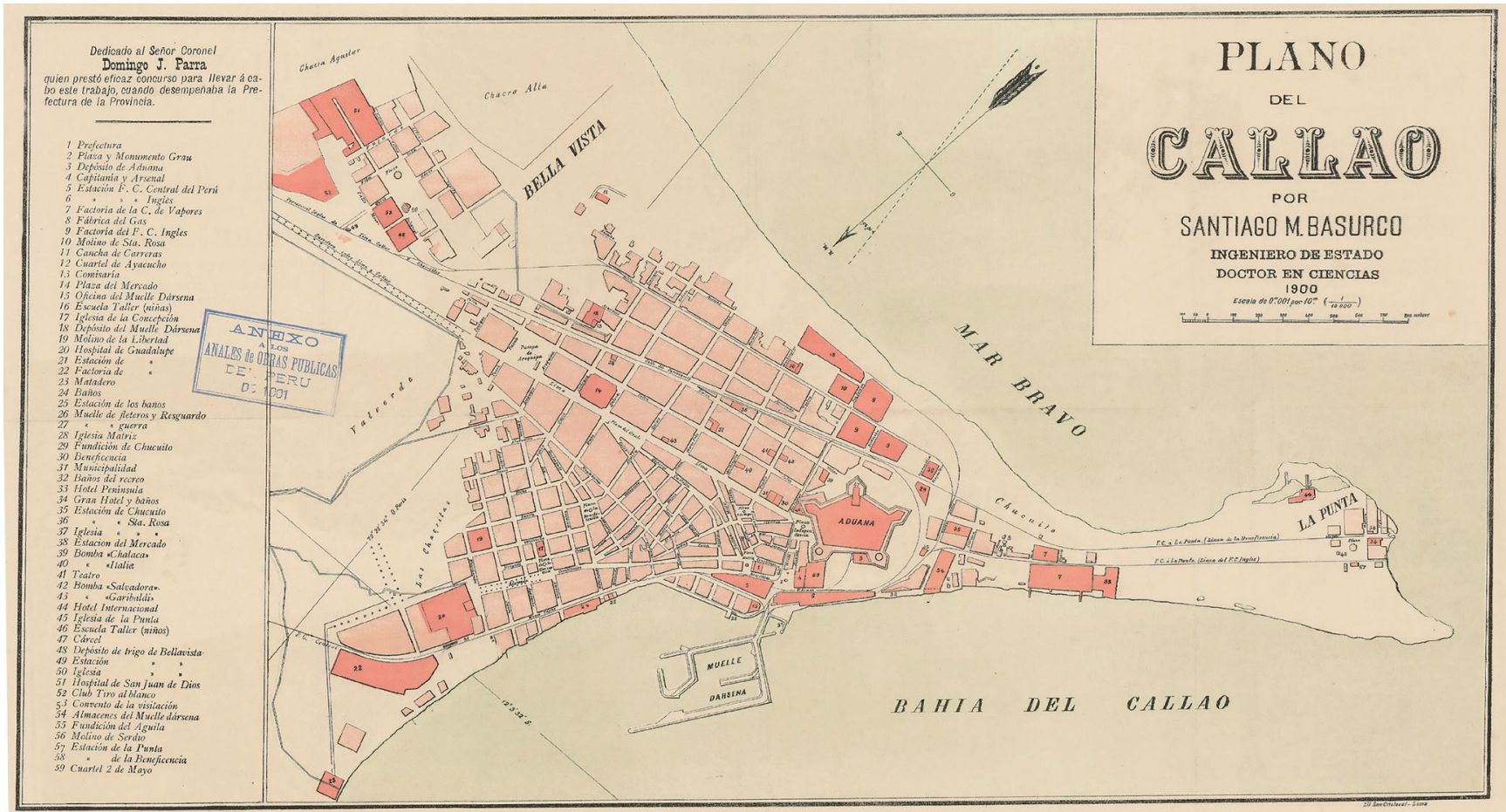

y comercio, así como a la presencia de los dos puertos más importantes del país: el Aeropuerto Internacional Jorge Chávez y el Terminal Portuario del Callao, equipamientos que contribuyeron a su rápido crecimiento. Por consiguiente, en su imagen urbana coexisten los conglomerados urbanos de actividades industriales, comerciales y residenciales, en condiciones inadecuadas en la mayoría de los casos. 
devenir Vol. 3, Nº6, JULIO-DICIEMBRE 2016, PP. 98-124 - EstudIOS I ISSN 2312-7570

UNIVERSIDAD NACIONAL DE INGENIERÍA, LIMA

Figura 11. Vista panorámica de la Plaza Grau y la bahía del Callao, 1970 Fuente: Panorámica de la Plaza Grau, 1976 [Fotografía]. (19 de noviembre de 2015). Recuperado el 17 de mayo de 2016 de El Callao que se nos fue [en línea].

Figura 12. Delimitaciones del Centro Histórico del Callao hasta la actualidad

Fuente: Elaboración propia, 2016.
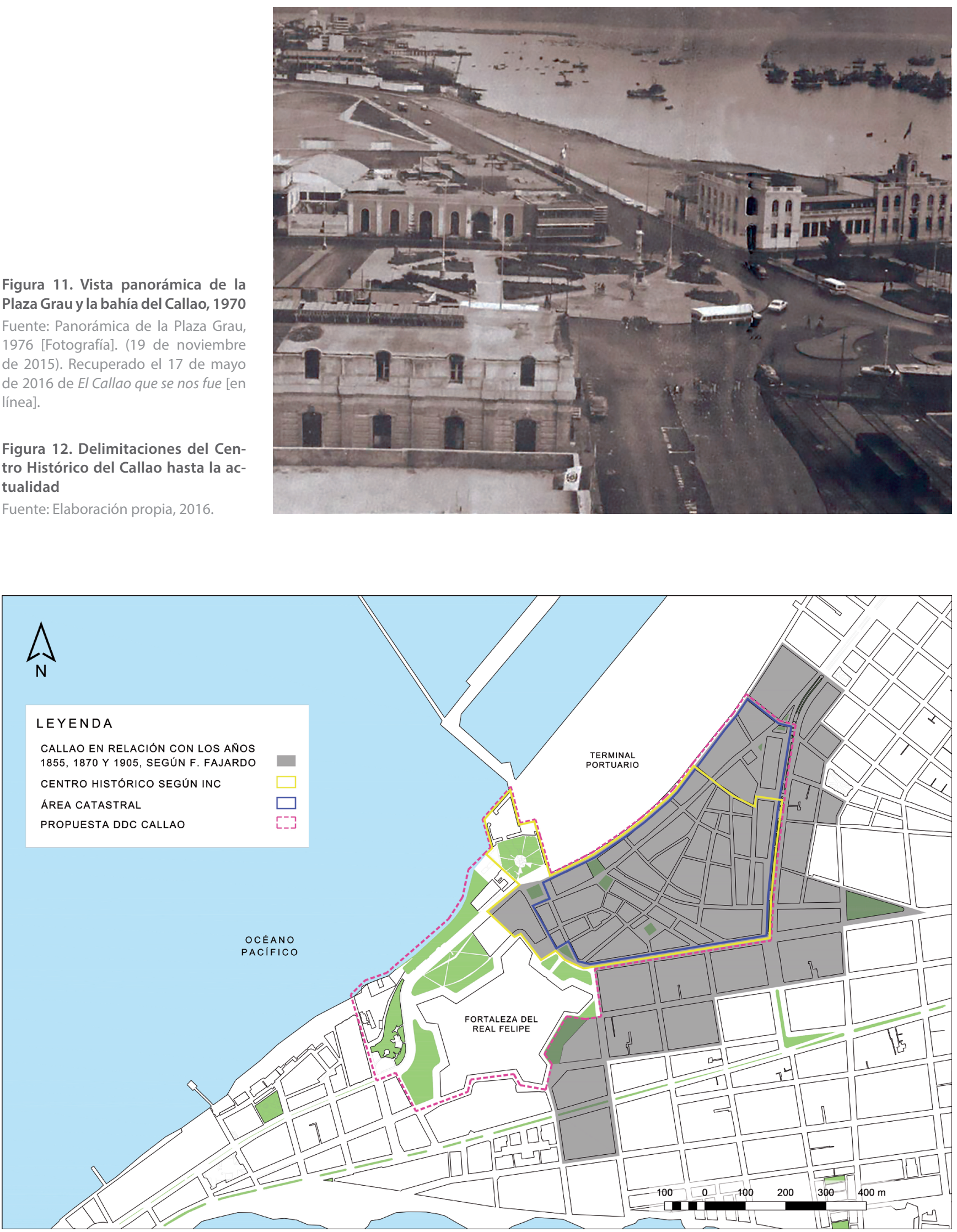
Las actividades portuarias, el puerto y el mar son también parte importante de la imagen urbana y la identidad chalaca. Posterior a su rol en el proceso de Independencia, el puerto desempeñó un papel importante en la defensa peruana: durante el Motín del Callao en 1824, el Combate de 2 de Mayo en 1866, y la Guerra del Pacífico entre 1879 y 1883.

Asimismo, un elemento trascendental en la historia del Perú es la Fortaleza del Real Felipe; edificación que forma parte del centro histórico y que soportó en 1820 el bloqueo impuesto por la escuadra libertadora desde el arribo de San Martín a Paracas hasta la capitulación de La Mar (Quiroz, 2007). Se le llamó Castillo de la Independencia hasta 1925.

Por último, como resultado del civismo chalaco, se otorgó a la ciudad del Callao en 1834 el lema "La fiel y generosa ciudad del Callao, asilo de las leyes y de la libertad".

\section{Valoración del centro histórico y su patrimonio inmueble}

Los límites del espacio denominado Centro Histórico del Callao -conocido también como Callao Monumental o Callao Antiguo, y mal llamado Barrio (de) Castilla ${ }^{7}$ - son imprecisos.

Según el Ministerio de Cultura, el área del centro histórico forma parte de la Zona Monumental del Callao (Municipalidad Provincial del Callao, 2010). Sin embargo, esta área y la delimitación catastral, ${ }^{8}$ además de ser discordantes, son incorrectas, como lo comprueba el estudio de López y Ramos $(1974)^{9}$ y la existencia de una propuesta de delimitación del centro histórico ${ }^{10}$ (Figura 12). De igual modo, cabe mencionar que la delimitación de la zona monumental encierra actualmente áreas inexistentes o que presentan drásticas modificaciones debido, en su mayoría, al crecimiento del terminal portuario.

Por lo tanto, sobre la base de la cartografía histórica y considerando las edificaciones existentes hasta la actualidad, se propone aquí la delimitación del Centro Histórico del Callao, ${ }^{11}$ que abarca el área urbana original y la Fortaleza del Real Felipe y su entorno, y que ocupa una extensión de 45.2 hectáreas distribuidas en 47 manzanas, 32 calles y 11 espacios urbanos entre plazas y parques (Figura 13).

Dentro de estos límites, son Patrimonio Cultural de la Nación 70 monumentos (2 como arquitectura militar y 68 como arquitectura civil doméstica) y 16 ambientes urbanos monumentales ( 2 plazas y 14 vías). De igual manera, se proponen 166 bienes como de valor monumental, de los cuales 154 fueron registrados en el Inventario del Patrimonio Monumental Inmueble del Centro Histórico del Callao (Soria, 1994; Figura 14).

Con respecto al estado de conservación, del total de monumentos 6 no existen en la actualidad, 2 han perdido completamente su valor patrimonial, otros 2 conservan la mitad de la construcción y 5 están abandonados. En ningún caso se ha retirado la condición de monumento (Figura 15).

Según la clasificación de valores propuesta, este patrimonio posee generalmente valores formales, como son los artísticos y de conjunto, debido a que las edificaciones

7. Según el director de la DDC Callao, el Lic. Fernández Valle, que el centro histórico sea denominado'barrio Castilla' es una muestra de la pérdida de identidad de la población:"no existe ningún barrio Castilla, [...] hay una calle Castilla como hay una calle Libertad, una calle Salaverry, pero no hay un barrio" (Conferencia del Ministerio de Cultura, julio de 2016).

8. Área catastral según documentos obtenidos de la DDC Callao, 2013.

9. En el Plano del Callao en relación con los años 1855, 1870 y 1905 elaborado por el Sr. F. Fajardo.

10. Propuesta realizada por la DDC Callao en 2015, no aprobada por el Ministerio de Cultura hasta la fecha.

11. Sin embargo, se considera necesaria la opinión por parte de los pobladores locales para no crear incongruencias entre los imaginarios urbanos ya establecidos y la propuesta técnica. 
devenir Vol. 3, N6, JULIO-DICIEMBRE 2016, PP. 98-124 - EstudIOS I ISSN 2312-7570

UNIVERSIDAD NACIONAL DE INGENIERÍA, LIMA

Figura 13. Delimitación actual de la Zona Monumental del Callao y delimitación propuesta del Centro Histórico del Callao, 2016

Fuente: Elaboración propia, 2016.

Figura 14. Patrimonio histórico inmueble en el Centro Histórico del Callao y bienes inmuebles propuestos, 2015

Fuente: Elaboración propia sobre la base de dispositivos legales de Declaración del Patrimonio Cultural de la Nación; y Soria, 1994, 2016.
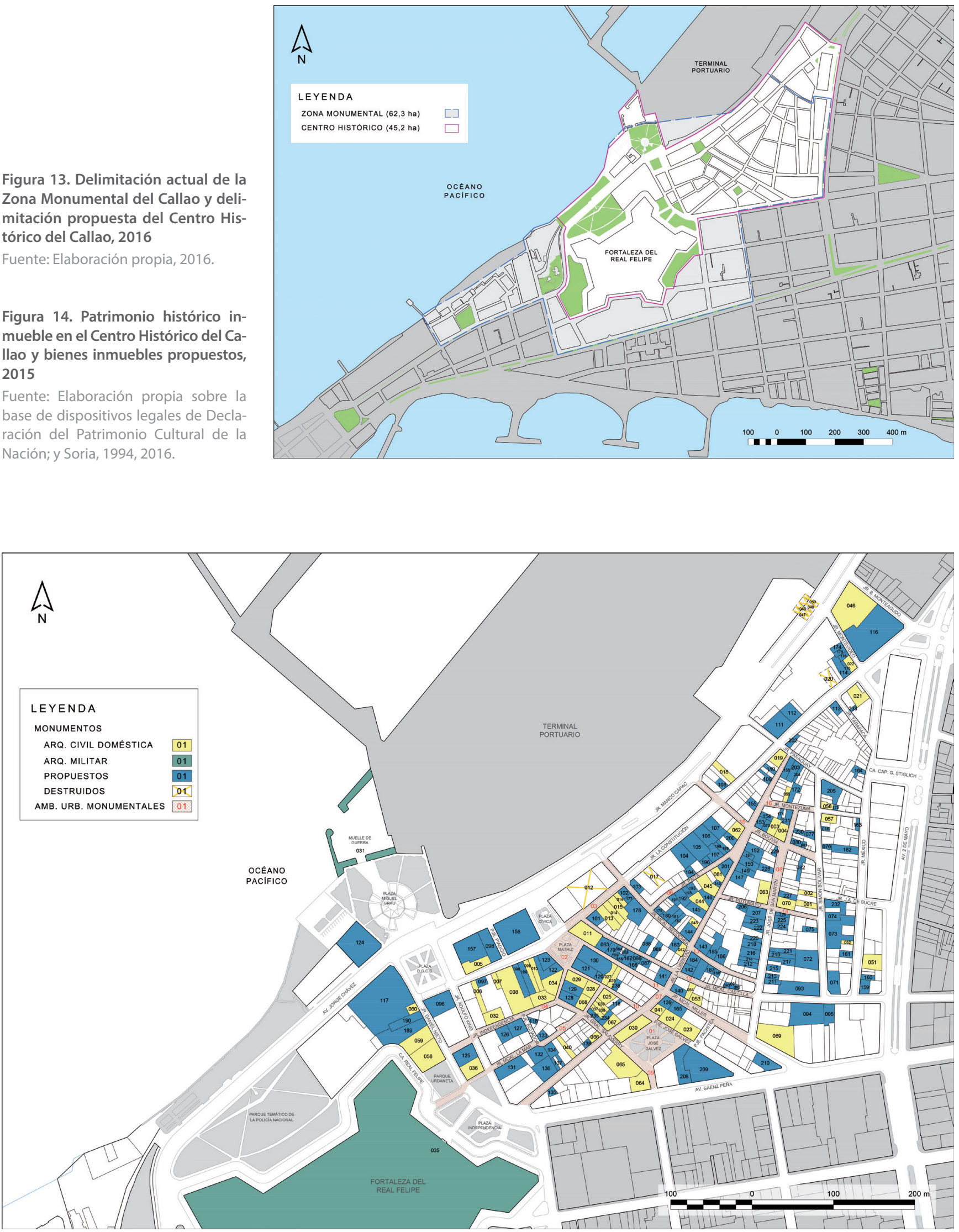
muestran unidad y armonía en la composición de sus frentes al estar conformados por elementos que corresponden a un mismo lenguaje formal, y están dispuestos siguiendo un ritmo constante y ordenado. Algunos inmuebles presentan elementos singulares, además de relevantes en su hechura tanto en términos estéticos como técnicos, entre los que destacan balcones, molduras y relieves decorativos, y cornisas y balaustradas que recorren por completo los frentes, lo cual les brinda unidad. Estos inmuebles usualmente están compuestos de varias unidades habitacionales y, en algunos casos, de locales comerciales en el piso bajo.

En cuanto a los bienes culturales de valor simbólico, a pesar de la importancia del puerto en la historia del Perú, son muy pocos los que se encuentran en esta área: entre ellos, la Fortaleza del Real Felipe y el Muelle de Guerra, que además poseen valor formal.

En cuanto a las declaraciones de los bienes inmuebles del centro histórico como integrantes del patrimonio cultural, se han realizado en cinco etapas (tomando como referencia el año de publicación de cada dispositivo legal; Figura 16):

- Primera declaración: Sin remisión a informes técnicos

- Segunda declaración: Aunque solo menciona "antecedentes adjuntos", tiene como referencia los documentos elaborados por la Junta Deliberante Metropolita-
Figura 15. Estado de conservación de los monumentos en el Centro Histórico del Callao, 2015

Fuente: Elaboración propia, 2016.

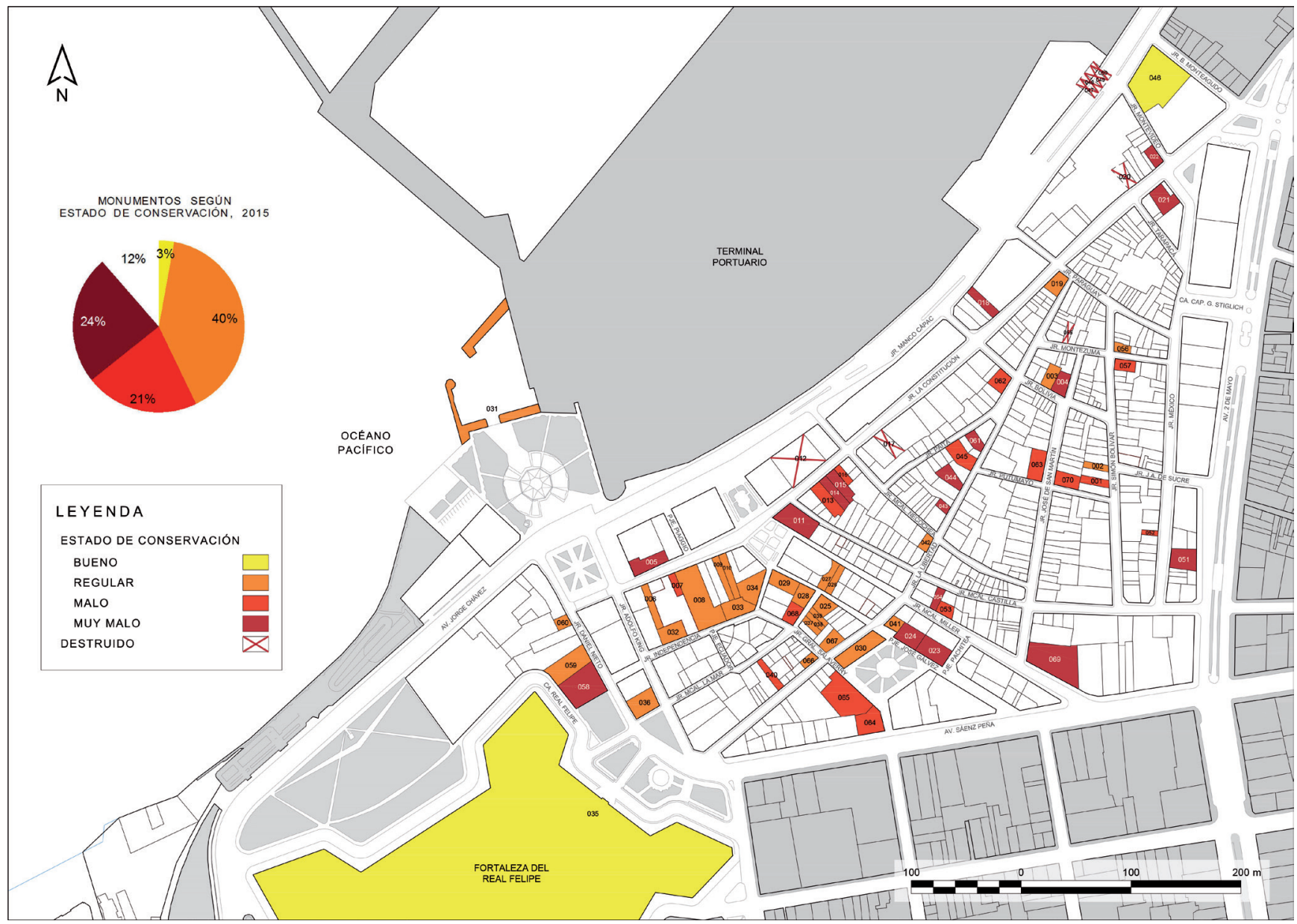


devenir Vol. 3, Nº6, JULIO-DICIEMBRE 2016, PP. 98-124 - EstudIOS I ISSN 2312-7570

UNIVERSIDAD NACIONAL DE INGENIERÍA, LIMA

Figura 16. Cantidad de monumentos y ambientes urbanos monumentales en el Centro Histórico del Callao según año de declaración Fuente: Elaboración propia, 2016.

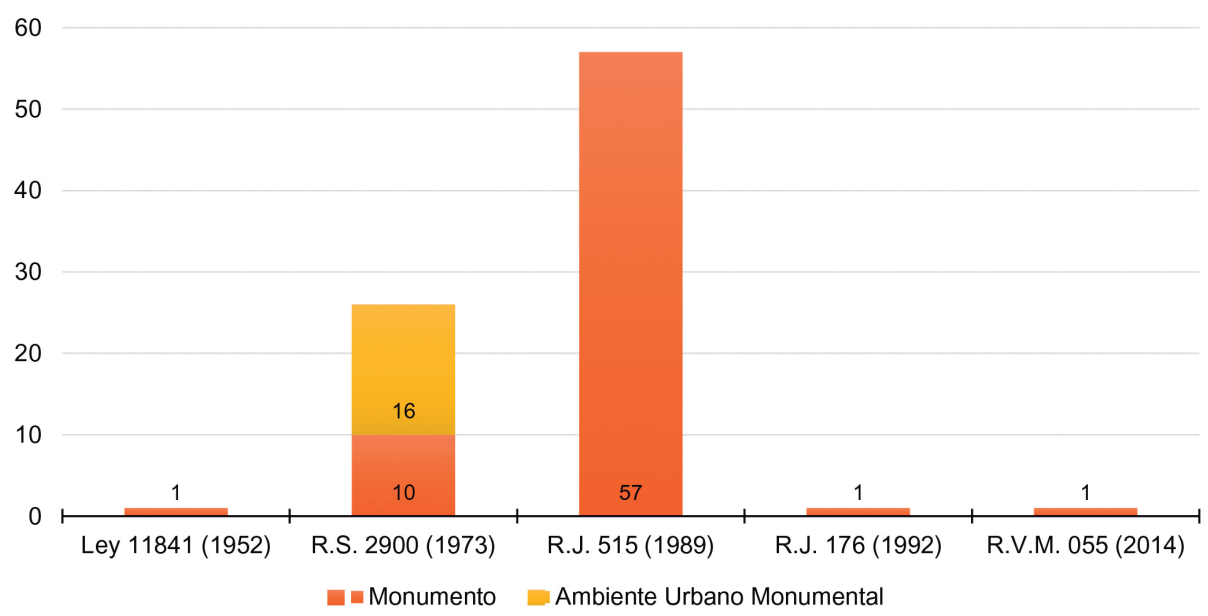

na (1962-1963), cuyo informe contiene listas de ambientes urbanos monumentales coloniales y republicanos, de ambientes y elementos paisajísticos, y de monumentos de la época colonial y republicana. Estas se complementan con fichas históricas y de calificación, informes estéticos y técnicos para su conservación y restauración, monografías, y fotos y planos de cada bien inmueble.

- Tercera declaración: Fichas básicas de identificación para cada uno de los bienes inmuebles, sin documentos que sustenten su valoración

- Cuarta declaración: Sin acceso al oficio que hace referencia

- Quinta declaración: Informes técnicos que presentan una extensa investigación

Es importante mencionar el informe elaborado por la Junta Deliberante Metropolitana (1962-1963), un trabajo de identificación y clasificación de monumentos y ambientes urbanos que considera parte del actual patrimonio histórico inmueble del Centro Histórico del Callao los 16 ambientes monumentales inmuebles y 25 de los 54 monumentos listados. Su propuesta de clasificación, tanto para ambientes urbanos monumentales como para monumentos, está dividida en i) clase, (ii) categoría y iii) calidad, y los valores patrimoniales reconocidos son los valores histórico, estético o artístico, arquitectónico y urbanístico. Según este informe, la mayor parte de los bienes inmuebles del centro histórico son de la clase 'monumento artístico' y 'ambiente urbano o paisajístico monumental artístico', cuyos valores pueden ser estéticos o artísticos, arquitectónicos, urbanísticos e histórico-artísticos.

Cabe subrayar que, en la segunda, tercera y cuarta declaración, los bienes inmuebles han sido propuestos por personal técnico. A pesar de la existencia de algunos documentos que sustentan los criterios de selección, estos son comúnmente desconocidos por la comunidad local, y su utilización en la promoción y gestión del patrimonio es nula. Más aun, los instrumentos utilizados para su identificación han sido diferentes en cada una de las declaraciones, sin establecer relación entre uno y otro, ni plantear una mejora. En general, el estudio de bienes inmuebles para su selección como patrimonio cultural consta de fichas de registro, fotos, planos y, en algunos casos, de informes técnicos.

Por otra parte, pese a existir procesos de registro, inventario y catalogación, la identificación de los bienes inmuebles del centro histórico se ha realizado únicamente a través de fichas de inventario, cuya estructura, aunque más compleja que una ficha de registro, es deficiente. 
Tabla 2. Registros e inventarios por año para el Centro Histórico del Callao al 2016

\begin{tabular}{|c|c|c|c|c|}
\hline Año & Nombre & Entidad ejecutora & Contenido & Área \\
\hline 1963 & $\begin{array}{l}\text { Informe de la comisión } \\
\text { de calificación de los } \\
\text { monumentos coloniales } \\
\text { y republicanos }\end{array}$ & $\begin{array}{l}\text { Junta Deliberante } \\
\text { Metropolitana de } \\
\text { Monumentos Históricos, } \\
\text { Artísticos y Lugares } \\
\text { Arqueológicos de Lima }\end{array}$ & Propuesta & $\begin{array}{l}\text { Lima Metro- } \\
\text { politana (y } \\
\text { Chilca) }\end{array}$ \\
\hline 1989 & $\begin{array}{c}\text { Proyecto de inventario, } \\
\text { registro y catalogación } \\
\text { del Centro Histórico del } \\
\text { Callao }\end{array}$ & $\begin{array}{l}\text { Convenio Instituto } \\
\text { Nacional de Cultura y } \\
\text { Corporación de Desa- } \\
\text { rrollo del Callao }\end{array}$ & Propuesta & $\begin{array}{l}\text { Distrito del } \\
\text { Callao }\end{array}$ \\
\hline $1994 a$ & $\begin{array}{l}\text { Inventario del patrimo- } \\
\text { nio monumental inmue- } \\
\text { ble - Lima: valles de } \\
\text { Chillón, Rímac y Lurín }\end{array}$ & $\begin{array}{l}\text { Convenio Facultad de } \\
\text { Arquitectura, Urba- } \\
\text { nismo y Artes de la } \\
\text { Universidad Nacional de } \\
\text { Ingeniería y Fundación } \\
\text { Ford }\end{array}$ & $\begin{array}{l}\text { Propuesta e } \\
\text { Inventario (mo- } \\
\text { numentos y am- } \\
\text { bientes urbanos } \\
\text { monumentales) }\end{array}$ & $\begin{array}{l}\text { Lima Metro- } \\
\text { politana }\end{array}$ \\
\hline $1994 b$ & $\begin{array}{c}\text { Inventario del patrimo- } \\
\text { nio monumental inmue- } \\
\text { ble del Centro Histórico } \\
\text { del Callao }\end{array}$ & $\begin{array}{c}\text { Judith Soria León para } \\
\text { Instituto Metropolitano } \\
\text { de Planificación y Cor- } \\
\text { poración de Desarrollo } \\
\text { del Callao }\end{array}$ & $\begin{array}{c}\text { Propuesta e } \\
\text { Inventario (monu- } \\
\text { mentos) }\end{array}$ & $\begin{array}{l}\text { Distrito del } \\
\text { Callao }\end{array}$ \\
\hline 2010 & $\begin{array}{l}\text { [Fichas de monumentos } \\
\text { históricos] }\end{array}$ & $\begin{array}{c}\text { Gobierno Regional del } \\
\text { Callao }\end{array}$ & $\begin{array}{l}\text { Inventario (mo- } \\
\text { numentos, am- } \\
\text { bientes urbanos } \\
\text { monumentales y } \\
\text { zonas monumen- } \\
\text { tales) }\end{array}$ & $\begin{array}{l}\text { Provincia } \\
\text { Constitu- } \\
\text { cional del } \\
\text { Callao }\end{array}$ \\
\hline
\end{tabular}

Los registros e inventarios existentes son cinco (ver Tabla 2), cada uno de ellos elaborado por diferentes instituciones. Aunque la Corporación de Desarrollo del Callao, actual Gobierno Regional del Callao, ha participado en tres momentos (1989, 1994a y 2010), la información registrada presenta incongruencias entre sí..

A nivel internacional, el Comité del Patrimonio Mundial establece como estrategia para la gestión de los bienes patrimoniales "la definición de procedimientos para un sistema de seguimiento efectivo del estado de conservación" (Hooff, 1999, p. 10), y recomienda presentar informes periódicos. Por ello, la Organización de las Naciones Unidas para la Educación, la Ciencia y la Cultura (UNESCO) invita a los Estados Partes ${ }^{12}$ a presentar un informe periódico cada seis años que incluya el estado de conservación de los bienes del patrimonio mundial ubicados en sus territorios (UNESCO, s.f.).

12. Los Estados Partes son países que se han adherido a la Convención del Patrimonio Mundial, con lo cual cada uno de ellos se compromete a conservar no solo los sitios del patrimonio mundial situados en su territorio, sino también a proteger su patrimonio nacional. [Traducción propia]. Recuperado de http://whc. unesco.org/en/statesparties/. 
Al establecer una comparación entre los lineamientos nacionales e internacionales, se evidencia que hacen falta procedimientos para el seguimiento como parte de la gestión del patrimonio. Sin una actualización periódica, los inventarios no pueden ser empleados como instrumentos para este fin.

En resumen, lo más resaltante de la valoración del centro histórico, además de la delimitación de la zona monumental vigente, son sus límites imprecisos y los criterios complejos y no estandarizados seguidos por los organismos públicos para la selección y la protección de los bienes culturales inmuebles.

En este contexto, es oportuno reproducir un extracto de la Ley del Patrimonio Histórico Español (1985):

La ley dispone también las fórmulas necesarias para que esa valoración [de los bienes culturales] sea posible, pues la defensa del Patrimonio Histórico de un pueblo no debe realizarse exclusivamente a través de normas que prohíban determinadas acciones o limiten ciertos usos, sino a partir de disposiciones que estimulen a su conservación y, en consecuencia, permitan su disfrute y faciliten su acrecentamiento. [...] De esa forma se impulsa una política [...] que complemente la acción vigilante con el estímulo educativo, técnico y financiero, en el convencimiento de que el Patrimonio Histórico acrecienta y se defiende mejor cuanto más lo estiman las personas que conviven con él (Preámbulo, párr. 7-8).

De ahí que un adecuado proceso de reconocimiento o valoración del patrimonio se oriente según normativas complementarias a la legislación, con la finalidad de establecer políticas para la preservación de los bienes culturales como parte de la gestión del patrimonio cultural.

\section{Gestión del patrimonio inmueble en el Perú y el Callao}

Los organismos públicos encargados de las acciones de protección y conservación del Patrimonio Cultural de la Nación son el Ministerio de Cultura, y el gobierno regional y la municipalidad del ámbito territorial donde el bien cultural se emplaza. De ahí que, en el Centro Histórico del Callao, intervengan i) el Ministerio de Cultura, ii) el Gobierno Regional del Callao y iii) la Municipalidad Provincial del Callao.

La legislación y la normativa en materia de bienes culturales inmuebles para cada uno de los organismos públicos se condensa en la Tabla 3. Cabe mencionar dos casos:

-Ley № 30230 (2014): Modifica la Ley № 28296, pero no deroga ni modifica la Ley № 27580 , lo que ocasiona la coexistencia de dos normas que regulan de forma incongruente la autorización para ejecutar alguna obra en un bien cultural inmueble (Valencia Gibaja, 2014).

- Ley No 29164 (2007): Busca establecer condiciones que favorezcan y promocionen el desarrollo de la inversión privada, de forma que permita acciones de protección en los bienes culturales inmuebles a través de concesiones para la prestación de servicios turísticos en zonas que determine el Ministerio de Cultura según la iniciativa de gobiernos regionales, locales, y entidades públicas competentes y particulares.

Sobre esta última ley, el Comité Peruano del Consejo Internacional de Museos (ICOM Perú) hace un pronunciamiento en el cual manifiesta que

....la puesta en valor de un sitio o monumento arqueológico requiere de la elaboración de dos instrumentos técnicos fundamentales: (a) un Plan Maestro, que incluya a los bienes culturales dentro de una planificación integral [...y] (b) un Plan de Manejo [...], que defina en detalle las acciones de gestión para garantizar la preservación, conservación y puesta en valor del bien cultural (como se citó en Echevarría, 2008, párr. 20). 
Tabla 3. Dispositivos de legislación y normativa en relación al patrimonio cultural inmueble por organismo público para el distrito del Callao a 2016

\section{Dispositivo}

Nivel internacional

R.L. N. ${ }^{\circ} 25030$

R.L. N. ${ }^{\circ} 28159$

Ley N. ${ }^{\circ} 22680$

Ley N. 22682

\section{Ministerio de Cultura}

Constitución Política del Perú

Código Penal

Ley N. 29565

Ley N. 28296

Ley N. 27580

\section{Ministerio de Comercio Exterior y Turismo}

Ley N. 29164

Ley N. ${ }^{\circ} 30230$

\section{Ministerio de Vivienda, Constucción y Saneamiento}

Reglamento Nacional de Edificaciones

Ley N.o 29415

\section{Gobierno Regional del Callao}

Ley N. ${ }^{\circ} 27867$

\section{Municipalidad Provincial del Callao}

Ley N. 27972

Reglamentación edilicia de la zona monumental del Callao antiguo
Aprueba la Convención para la Protección de los Bienes Culturales en caso de conflicto Armado. Unesco, La Haya 1954.

Aprueba la adhesión del Perú al Segundo protocolo de la Convención para la Protección de los Bienes Culturales en caso de conflicto Armado. Unesco, La Haya 1954.

Aprueba la Convención sobre las medidas que deben adoptarse para prohibir e impedir la importación, la exportación y la transferencia de propiedad ilícita de bienes culturales. Unesco, París 1979.

Aprueba la Convención sobre defensa del patrimonio arqueológico, histórico y artístico de las Naciones Americanas. Convención de San Salvador OEA, Santiago de Chile 1979.

Art. ${ }^{\circ} 21$

Tít. VIII

Ley de creación del Ministerio de Cultura.

Ley general del patrimonio cultural de la Nación.

Dispone medidas de protección que debe aplicar el ministerio para la ejecición de obras en bienes culturales inmuebles.

Ley de promoción del desarrollo sostenible de servicios turísticos en los bienes inmuebles, integrantes del patrimonio cultural de la Nación.

Establece medidas tributarias, simplificación de procedimientos y permisos para la promoción y dinamización de la inversión del país (art.으).

Norma Técnica A.140, Bienes culturales inmuebles y zonas monumentales.

Ley de saneamiento físico legal de predios tugurizados con fines de renovación urbana.

Ley orgánica de gobiernos regionales.

Ley orgánica de municipalidades.

Reglamento para la conservación de la estructura urbana de la zona monumental del Callao. 
ICOM Perú añade que ambos planes deben involucrar la participación de la comunidad local ${ }^{13}$ "con la finalidad de que se identifique con la significación del monumento, colabore en su defensa y mantenimiento, y se beneficie con las inversiones que se realicen en la ejecución de las obras [de conservación y restauración]" (como se citó en Echevarría, 2008, párr. 22). Se considera que estos planes son también aplicables al patrimonio histórico inmueble.

Ahora bien, los dispositivos legales y normativos no deben desplegarse de modo uniforme sobre todos los bienes culturales, sino establecer "distintos niveles de protección que se correspondan con las diferentes categorías [del patrimonio]" (Gobierno de España, 1985, Preámbulo, párr. 10).

Sin embargo, entre los instrumentos técnicos para la gestión del patrimonio, tanto para el distrito del Callao como para la provincia, no se encontraron planes de acciones coordinadas entre los organismos ni planes económico-financieros para la conservación del patrimonio histórico inmueble. En cuanto a los planes de prevención contra riesgos, el Plan regional de operaciones de emergencia del Callao 2016, que orienta las acciones de respuesta en caso de emergencia o desastre, no estipula acciones respecto al patrimonio inmueble.

Por otra parte, corresponde a las municipalidades planificar el desarrollo integral de sus circunscripciones, lo que comprende el patrimonio inmueble, para lo cual cuentan con tres instrumentos técnico-normativos en materia de acondicionamiento territorial y desarrollo urbano: i) planes urbanos ${ }^{14}$, ii) plan específico y iii) planeamiento integral.

En este aspecto, la Municipalidad Provincial del Callao aprobó el Plan de Desarrollo Urbano de la Provincia Constitucional del Callao 2011-2022 (PDU 2011-2022) a fines de 2010 y lo suspendió temporalmente a inicios de 2011, con lo que se restableció la vigencia del plan urbano anterior, el Plan Urbano Director de la Provincia Constitucional del Callao para el período 1995-2010 (PUD 1995-2010). Meses después, el tiempo de suspensión se amplió hasta la aprobación del Plan de Desarrollo Metropolitano, ${ }^{15}$ con plazo perentorio de cuatro años.

Cumplido este plazo en 2015, la municipalidad provincial restituyó la vigencia del PDU 2011-2022, y solicitó al Ministerio de Vivienda, Construcción y Saneamiento considerar su facultad para elaborar, aprobar y aplicar un plan metropolitano de manera autónoma. Ese mismo año, la municipalidad dispuso la elaboración del Plan de Desarrollo Metropolitano de la Provincia Constitucional del Callao al 2035, y suspendió los alcances del PDU 2011-2022 en los aspectos de zonificación, vialidad y complementarios hasta la aprobación del nuevo plan, lo cual implicó nuevamente la aplicación del PUD 19952010 y sus modificatorias. Hasta julio de 2016, se desconoce el estado del PDM.

Estos sucesos condicionan la gestión del Centro Histórico del Callao. Así, por ejemplo, la zonificación urbana correspondiente al centro histórico es de zona monumental, y de zona mixta de densidad media hacia el Norte; ambas caracterizadas por el desarrollo complementario de uso residencial, comercial, de servicios e industrial produc-

13. Cabe mencionar que uno de los problemas para la adecuada gestión del patrimonio es la existencia de poseedores o tenedores de los predios de la mayor parte del Centro Histórico del Callao.

14. Comprenden: i) Plan de Acondicionamiento Territorial (PAT), ii) Plan de Desarrollo Metropolitano (PDM), iii) Plan de Desarrollo Urbano, iv) Plan Urbano Distrital y v) Esquema de Ordenamiento Urbano. La organización físico-espacial del territorio provincial, con competencias sobre el patrimonio cultural y la inversión pública y privada, está orientada y regulada por el PAT.

15. El Decreto Supremo N. ${ }^{\circ}$ 004-2011-VIVIENDA aprueba el Reglamento de Acondicionamiento Territorial y Desarrollo Urbano, el cual señala que, en el caso del área metropolitana conformada por las provincias de Lima y del Callao, corresponde a la Municipalidad Metropolitana de Lima y a la Municipalidad Provincial del Callao elaborar el PDM, y los excluye de contar con un PAT. 
tiva no contaminante. Por otro lado, se mantiene vigente la Reglamentación edilicia de la zona monumental del Callao antiguo, que data de 1990. Este dispositivo, además de la zona monumental, norma las acciones en zonas circundantes y naturales. ${ }^{16}$ Cabe mencionar que el PDU 2011-2022 (actualmente suspendido) incluía, como parte de sus instrumentos de gestión, el "Reglamento para el Patrimonio Cultural Inmueble del Callao", que normaba los parámetros urbanos para la conservación y recuperación de las zonas monumentales y arqueológicas, y que reconocía dentro de la Zona Monumental del Callao "áreas de diferentes características morfológicas y funcionales": i) el centro histórico, ii) la Fortaleza del Real Felipe y su entorno, y iii) el barrio de Chucuito (Municipalidad Provincial del Callao, 2010). Hasta 2016, la Dirección Desconcentrada de Cultura del Callao (DDC Callao) se encontraba desarrollando el estudio para la delimitación del centro histórico, y la propuesta para la nueva delimitación y reglamentación de la Zona Monumental del Callao.

Con respecto a los proyectos para la conservación del centro histórico, en la Tabla 4 se registran los de inversión pública realizados en los últimos 10 años, desde 2006.

Uno de estos proyectos fue el Proyecto de Renovación Urbana del Centro Histórico, concluido en 2012, que ha tenido un significativo impacto urbano en el lugar. Según su ficha de registro, este proyecto tenía por objetivo "lograr adecuadas condiciones de transitabilidad [sic], alumbrado público y mobiliario ornamental ${ }^{17}$ en el Centro Histórico del Callao" (Ministerio de Economía y Finanzas, 2016, sección 3.3). Los beneficiarios directos ${ }^{18}$ eran 9,036 personas, y el horizonte de evaluación del proyecto era de 10 años, el cual incluía un mantenimiento rutinario anual y uno periódico cada cinco años. Así, se rehabilitaron, de forma parcial y por cuadras, las calzadas y aceras de 20 calles ubicadas en el interior del centro histórico, y se mejoró parcialmente el mobiliario urbano.

Luego de cuatro años, las vías rehabilitadas se encontraban en mal estado de conservación, tanto las calzadas como las aceras: presentaban grietas, humedad y grama, y desgaste o pérdida de elementos, como los adoquines de piedra en el caso de las calzadas. Asimismo, el alumbrado ornamental, colocado a distancias variables, irrumpía con elementos de las edificaciones, como los balcones. Finalmente, la señalización de calles era inexistente (Figura 17).

Además, se llevó a cabo otros dos proyectos, realizados bajo la modalidad Asociación Público-Privada (APP), que influyeron en la dinámica del centro histórico. El primero es el proyecto del Complejo hospitalario Alberto Leopoldo Barton Thompson, inaugurado en diciembre de 2014 y edificado en la cuadra 3 de la Av. Sáenz Peña por la asociación entre el Seguro Social de Salud (EsSalud) y la Sociedad Operadora Callao Salud; el segundo, el proyecto Modernización Semafórica en el Centro Histórico, desarrollado y financiado por el Consorcio Tránsito Ciudadano para la Municipalidad Provincial del Callao en 2015, y otorgado en concesión a la empresa SUTEC, como parte de la primera etapa del Plan de Modernización de Intersecciones Semafóricas en el Centro Histórico del Callao. Este proyecto implementó nueve cruces semafóricos en la Av. Sáenz Peña y dos en la Av. Miguel Grau.

\footnotetext{
16. Para el centro histórico, la zona natural se ha modificado y ha quedado reducida al Muelle de Guerra, ubicado en la Plaza Grau.

17. Como parte de la mejora del mobiliario urbano, este proyecto consideró la iluminación ornamental (faroles de pie y faroles adosados en la pared); la señalización, tanto informativa como reguladora; y el equipamiento urbano, como tachos de basura y bancas ornamentales (Gobierno Regional del Callao, 2011).

18. Según la descripción, hace referencia a la población asentada en el espacio urbano del distrito del Callao, denominado 'Centro Histórico del Callao'.
} 
devenir Vol. 3, Nº, JULIO-DICIEMBRE 2016, PP. 98-124 - EstudIOS I ISSN 2312-7570

UNIVERSIDAD NACIONAL DE INGENIERÍA, LIMA

Tabla 4. Proyectos de inversión pública realizados en el Centro Histórico del Callao, 2006-2015

\begin{tabular}{|c|c|c|c|c|c|}
\hline Año & Nombre del proyecto & Código SNIP & Sector & Entidad ejecutora & Monto invertido (S/) \\
\hline 2006 & -- & -- & -- & -- & -- \\
\hline 2007 & -- & -- & -- & -- & -- \\
\hline \multirow{2}{*}{2008} & $\begin{array}{c}\text { Proyecto de Renovación Urbana del } \\
\text { Centro Histórico del Callao (estudio } \\
\text { de pre-inversión) }\end{array}$ & -- & Gestión & $\begin{array}{l}\text { Gobierno Regional } \\
\text { del Callao }\end{array}$ & 174454 \\
\hline & $\begin{array}{c}\text { Construcción de Salas de Convencio- } \\
\text { nes y Reuniones en la Fortaleza Real } \\
\text { Felipe }\end{array}$ & 86849 & Saneamiento & $\begin{array}{l}\text { Municipalidad Pro- } \\
\text { vincial del Callao }\end{array}$ & 12652960 \\
\hline 2009 & $\begin{array}{l}\text { Construcción de Salas de Convencio- } \\
\text { nes y Reuniones en la Fortaleza Real } \\
\text { Felipe (liquidación de obra) }\end{array}$ & 86849 & Saneamiento & $\begin{array}{l}\text { Municipalidad Pro- } \\
\text { vincial del Callao }\end{array}$ & 225635 \\
\hline 2010 & - & - & - & - & - \\
\hline 2011 & $\begin{array}{c}\text { Mejoramiento urbano del Centro } \\
\text { Histórico del Callao }\end{array}$ & 177562 & Transporte & $\begin{array}{l}\text { Gobierno Regional } \\
\text { del Callao }\end{array}$ & 1801800 \\
\hline 2012 & $\begin{array}{c}\text { Mejoramiento urbano del Centro } \\
\text { Histórico del Callao }\end{array}$ & 177562 & Transporte & $\begin{array}{l}\text { Gobierno Regional } \\
\text { del Callao }\end{array}$ & 946176 \\
\hline 2013 & $\begin{array}{l}\text { Mejoramiento urbano del Centro His- } \\
\text { tórico del Callao (liquidación de obra) }\end{array}$ & 177562 & Transporte & $\begin{array}{l}\text { Gobierno Regional } \\
\text { del Callao }\end{array}$ & 24873 \\
\hline 2014 & - & - & - & - & - \\
\hline 2015 & -- & -- & -- & -- & -- \\
\hline
\end{tabular}

Nota: Adaptado de "Proyectos de Inversión", Portal de Transparencia del Gobierno Regional del Callao y de la Municipalidad Provincial del Callao, 2016. SNIP = Sistema Nacional de Inversión Pública.

En síntesis, en 10 años se han realizado en el centro histórico cuatro proyectos de financiamiento tanto público como público-privado que corresponden principalmente al sector transporte.

Por último, entre las acciones de las entidades privadas, Casa y Arte -con la Exposición Peruana de Arquitectura, Decoración, Diseño y Paisajismo (conocida como 'Casa Cor Perú') - ha intervenido en el Centro Histórico del Callao en sus ediciones XVI y XX, de 2011 y 2015 respectivamente. En ambas, se restauró el Edificio Ronald y, en la última edición, también la Casa Valega -ambos, patrimonio cultural-. Además, en la vigésima edición, se recuperó y puso en valor diversas fachadas y espacios urbanos, en asociación con el proyecto Fugaz bajo el nombre Festival Monumental Callao.

Desde setiembre de 2015, el conglomerado de empresas Fugaz está presente en el centro histórico con un proyecto de arte urbano que busca recuperar este espacio como lugar de convivencia entre la creatividad y el ambiente que lo acoge, y convertirlo en un sitio turístico y artístico a través del arte, la cultura y la inversión privada, involucrando a la comunidad ("Revalorizando el Callao", 2015). 


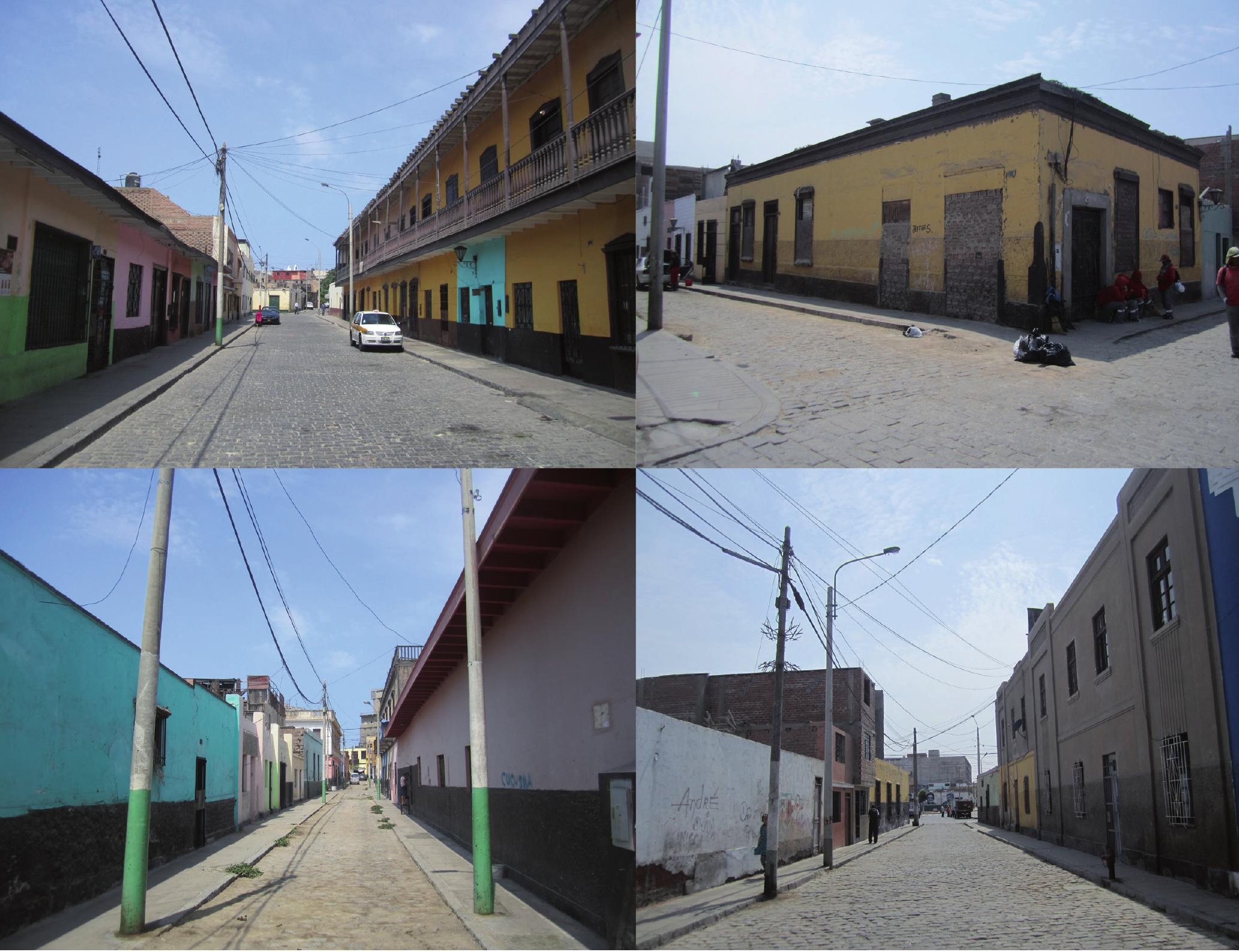

\section{Conclusiones}

El crecimiento indiscriminado de la Provincia Constitucional del Callao ha producido en su ciudad histórica una degradación socioeconómica, urbana y arquitectónica. Desde inicios del siglo XXI, el patrimonio inmueble del Centro Histórico del Callao se ha visto reducido y gran parte de este ha perdido su valor patrimonial (el $24.3 \%$ presenta un estado de conservación muy malo y se ha destruido el $11.4 \%$ de monumentos).

De las dos declaraciones más importantes, solo la publicada en 1973 es resultado de una calificación que distingue valoraciones. Sin embargo, el 81.4\% del patrimonio inmueble ha sido reconocido en la de 1989, de cuyo proceso de selección se desconocen los documentos que lo fundamentan.

\section{Valoración y normativa}

El inicio de la protección del patrimonio es la valoración; no obstante, se carece de procesos de reconocimiento que orienten los criterios de selección para sustentar adecuadamente lo que se protege. La Ley General del Patrimonio, aunque señala los valores que deben tener los bienes inmuebles para ser considerados culturales, prescinde de ellos al diseñar medidas de protección. Sin difusión de la valoración ni las medidas de protección, muchas edificaciones deterioradas por el paso del tiempo, el mal uso o la falta de mantenimiento son abandonadas a la espera de su destrucción.
Figura 17. Estado de calles rehabilitadas al 2016. De izquierda a derecha y de arriba hacia abajo: i) Jr. Castilla, cdra. 3; ii) Jr. Moctezuma, cdra. 2; iii) Jr. Putumayo, cdra. 2; y iv) Jr. Sucre, cdra. 1

Fuente: Archivo fotográfico Marsia Montañez, 2016. 
Por otra parte, la documentación existente respecto de cada bien cultural inmueble se encuentra disgregada: es imposible encontrar un dispositivo que reúna toda la información y la haga accesible. Más aun, los inventarios realizados -por distintas instituciones, sin una compatibilización de datos ni una actualización periódica- no tienen utilidad como instrumentos para el seguimiento del estado de conservación del patrimonio.

A nivel nacional, la existencia de numerosos dispositivos inconexos que tratan la protección del patrimonio impide su clara comprensión y hace necesario un único dispositivo técnico-legal. Al mismo tiempo, la normativa existente en la provincia del Callao es ácrona; está desfasada de su actual dinámica económica, social y cultural, y es incompatible con la trama urbana y el espacio construido existentes en el territorio.

\section{Gestión del patrimonio}

Para poder llevar a cabo la conservación del patrimonio, los organismos públicos requieren recursos. Sin embargo, más que una falta de recursos financieros, existe una escasez de recursos técnicos constituidos por procesos sistematizados y recursos humanos constituidos por personal técnico que permitan a la comunidad el acceso al conocimiento en materia de conservación, y que promuevan y faciliten la inversión privada. En el Callao, la realidad muestra que los procedimientos ejecutados por los organismos públicos frenan los proyectos de inversión privada; ello se debe, en parte, a las restricciones vigentes en cuanto al uso del patrimonio inmueble, y el empleo de nuevos materiales y tecnologías constructivas.

La inversión pública y privada en la provincia está orientada al desarrollo de infraestructura vinculada al equipamiento de carácter nacional presente en su territorio, con un significativo énfasis en el transporte. Las escasas intervenciones en el patrimonio inmueble realizadas por organismos públicos, si bien han pausado el deterioro del centro histórico, no han resultado en obras de calidad ni han contribuido al desarrollo urbano del lugar.

Además, la descoordinación y la falta de trabajo conjunto de tales organismos generan debilidad institucional en la provincia: la ausencia del Plan de Desarrollo Metropolitano, que requiere la coordinación entre las municipalidades de Lima y del Callao, y los inexistentes planes y programas para la protección del patrimonio que deben ser formulados entre el Ministerio de Cultura (DDC Callao) y la municipalidad provincial. El resultado es la carencia de procesos de reconocimiento y de protección del patrimonio en el distrito. La coexistencia de diferentes organismos, tanto gubernamentales como sectoriales, hace compleja la dinámica y necesario el cambio del paradigma de gestión.

En el ámbito internacional, existen sistemas de gestión del patrimonio cultural. Si bien es contraproducente reproducir políticas internacionales, la solución dista de descartarlas; es importante tener en cuenta sus pautas y adecuarlas a cada realidad.

Finalmente, la protección del patrimonio cultural necesita de la sociedad en su conjunto: si se desconoce qué proteger (una parte o el todo), por qué proteger (valoración), cómo proteger (procesos) y cuándo proteger (planes), la consecuencia será la ausencia de protección. La falta de una cultura de conservación del patrimonio inmueble por parte de los actores sociales -propietarios, posesionarios, inquilinos, funcionarios públicos y privadostiene consecuencias directas en el estado de conservación del Centro Histórico del Callao.

La existencia de proyectos de iniciativa privada deja entrever que la participación de la comunidad es un factor positivo para la recuperación del lugar. A pesar de ello, se considera necesaria la actuación conjunta y la participación activa de los organismos públicos que, a través de instrumentos técnico-legales, orienten su accionar para así evitar la gentrificación del centro histórico. En el presente trabajo se ha omitido su análisis, pero se considera oportuno evaluar la inversión privada junto a la participación de la comunidad y su impacto en el desarrollo de este centro histórico. 


\section{Referencias}

AgainErick. (28 de marzo de 2008). Districs of Lima (Map; Licencia CC BY-SA) [Mapa]. Recuperado de Wikimedia Commons [en línea].

Ballart i Hernández, J., Fullola i Pericot, J. M., \& Petit i Mendizábal, M. (1996). El valor del patrimonio histórico. Complutum, Extra 6(2), 215-224.

Construcción y Vivienda (Ed.). (setiembre/octubre, 2015). Revalorizando el Callao Monumental. Proyecta, 35, 33-39. Recuperado de https://issuu.com/construccionyvivienda/docs/proyecta_edicion_35_final

Dirección de Hidrografía y Navegación. (2011). Área de inundación, vías de evacuación y zonas de refugio en caso de tsunami: La Punta-Callao [Mapa]. Recuperado de Sistema de Seguridad y Defensa del Callao [en línea].

Echevarría López, G. T. (2 de mayo de 2008). Sobre la Ley 29164. Pronunciamiento. 10/3/08 [Entrada de blog]. Recuperado de http://ley29164.blogspot.pe/2008/05/sobre-la-ley-29164-pronunciamiento.html

Flores, W. (25 de agosto de 2015). [Fotografía de la bahía del Callao]. Recuperado de “Drone Monumental Callao", Monumental Callao [Álbum de Facebook, en línea].

Giannuzzi Cordano, F. \& Williams León, C. (1983). Estudio urbano del Centro Histórico del Callao (Trabajo de investigación sin publicar). Universidad Nacional de Ingeniería, Programa Académico de Arquitectura, Urbanismo y Artes, Lima, Perú.

Gobierno Regional del Callao. (2011). Estudio de preinversión a nivel de perfil: mejoramiento urbano del Centro Histórico del Callao, Provincia Constitucional del Callao [Informe]. Callao, Perú.

Gonzáles Zapata, R. (12 de enero de 2016). Muelle del Callao, año 1713 [Plano]. Recuperado de "Breve Historia del Puerto del Callao", El Callao que se nos fue [Álbum de Facebook, en línea].

Gonzáles Zapata, R. (12 de enero de 2016). Muelle del Callao, año 1855 [Plano]. Recuperado de "Breve Historia del Puerto del Callao", El Callao que se nos fue [Álbum de Facebook, en línea].

Gonzalinux. (18 de octubre de 2012). Plano del Callao por Santiago M. Basurco, 1900 [Plano]. Recuperado de "Plano del Callao en el año 1900", Richiegonzales: La tecnología a tu alcance [en línea].

Hayakawa Casas, J. C. (2015). Gestión del Patrimonio Cultural y Centros Históricos Latinoamericanos. Tendiendo puentes entre el patrimonio y la ciudad (2a ed.). Lima, Perú: Universidad Nacional de Ingeniería.

Hooff, H. van (1999). La convención del patrimonio mundial y el seguimiento del estado de conservación. En Instituto Andaluz del Patrimonio Histórico et al. (Eds.), Indicadores para la evaluación del estado de conservación de ciudades históricas (pp. 6-11). Sevilla, España: Junta de Andalucía - Comares.

Huhsunqu. (5 de julio de 2009). Mapa plantilla de las regiones y departamentos del Perú (Licencia CC BY-SA) [Mapa]. Recuperado de Wikimedia Commons [en línea].

Instituto Nacional de Defensa Civil, Programa de las Naciones Unidas para el Desarrollo. (2010). Mapa de microzonificación sísmica en el Centro Histórico de Lima (Cercado de Lima y Rímac), Villa María del Triunfo y Callao. En Instituto Nacional de Defensa Civil (Ed.), Atlas de Peligros del Perú (pp.419-423). Recuperado de http://www.indeci.gob.pe/atlas_10/index_final.html

Instituto Nacional de Estadística e Informática. (2007). Censos Nacionales 2007: XI de Población y VI de Vivienda. Lima, Perú: Autor.

Instituto Nacional de Estadística e Informática. (2015). Compendio estadístico Provincia Constitucional del Callao 2014. Lima, Perú: Autor.

Junta Deliberante Metropolitana de Monumentos Históricos, Artísticos y Lugares Arqueológicos de Lima. (1962-1963). Informes, estudios legales sobre los monumentos, los organismos tutelares y de planificación. Lima, Perú. 
devenir Vol. 3, Nº6, JULIO-DICIEMBRE 2016, PP. 98-124 - EstudIOS I ISSN 2312-7570

UNIVERSIDAD NACIONAL DE INGENIERÍ, LIMA

Gobierno de España. Ley 16/1985, de 25 de junio, del Patrimonio Histórico Español. Boletín Oficial del Estado, 155, pp. 20342-20352. Madrid (29 de junio de 1985). Recuperado de https:// www.boe.es/diario_boe/txt.php?id=BOE-A-1985-12534

López Más, M. \& Ramos Cebreros, V. (1974). Núcleo inicial primitivo del Callao, criterio de integración y estructuración (Trabajo de pregrado sin publicar). Universidad Nacional de Ingeniería, Programa Académico de Arquitectura, Urbanismo y Artes, Lima, Perú.

Ministerio de Economía y Finanzas. (14 de marzo de 2016). Mejoramiento urbano del Centro Histórico del Callao (SNIP 177562) [Ficha de registro]. Recuperado de Base de datos de los Proyectos de Inversión Pública http://ofi2.mef.gob.pe/bp/ConsultarPIP/frmConsultarPIP.asp?accion $=$ consultar\&txtCodigo $=177562$

Montañez Arica, J. (2016). [Infografía sobre la población del Callao]. Reproducido con autorización.

Municipalidad Provincial del Callao. (2010). Plan de Desarrollo Urbano de la Provincia Constitucional del Callao 2011-2022. Recuperado de http://www.municallao.gob.pe/contenidosMPC/ transparencia/plan-desarrollo-urbano-2011.html

Panorámica de la Plaza Grau, 1976 [Fotografía]. (19 de noviembre de 2015). Recuperado de El Callao que se nos fue [en línea].

Plano de la Plaza, Fuertes, y Población del Callao, hacia 1790. [Plano]. (19 de enero de 2014). Recuperado de "El puerto del Callao durante el Virreinato (II)", Blog Cátedra de Historia y Patrimonio Naval [en línea]. [El texto se conservó como el original].

Pombo Urdaneta, C. \& Camacho Herrera, J. (2010). Génesis de la democracia local en Colombia y la planeación participativa (Vol. 2). Bogotá, Colombia: Editorial Universidad del Rosario.

Organización de las Naciones Unidas para la Educación, la Ciencia y la Cultura. (2014). Gestión del patrimonio mundial cultural [Manual de referencia]. París, Francia: Autor. Recuperado de http://whc.unesco.org/en/managing-cultural-world-heritage/

Quiroz Chueca, F. (2007). Historia del Callao: de puerto de Lima a Provincia Constitucional. Lima, Perú: Fondo Editorial del Pedagógico San Marcos.

Rodríguez Alomá, P. (2008). El centro histórico: del concepto a la acción integral. Centro-h, 1, 51-64.

Soria León, J. \& IMP-Corde Callao. (1994). Inventario del Patrimonio Monumental Inmueble del Centro Histórico del Callao. Lima, Perú.

United Nations Educational, Scientific and Cultural Organization. (s.f.). Periodic Reporting [Traducción propia]. Recuperado de http://whc.unesco.org/en/periodicreporting/

Valencia Gibaja, F. A. (27 de noviembre de 2014). La Ley No 30230 y sus modificatorias a la Ley $N^{\circ}$ 28296 - Ley General del Patrimonio Cultural de la Nación [Entrada de blog]. Patrimonio Cultural. Recuperado de http://blog.pucp.edu.pe/blog/aleajactaes/2014/11/27/la-ley-n-30230y-sus-modificatorias-a-la-ley-n-28296-ley-general-del-patrimonio-cultural-de-la-naci-n/

Valenzuela, M. (2015). Políticas culturales y Estado-nación: las declaraciones del patrimonio histórico inmueble en el Perú entre 1821 y 2014. Devenir, 2(3), 8-21.

Vicuña Del Río, M. (2013). Las formas de la densidad residencial. El caso del Gran Santiago, Chile. En P. Bento et al. (Eds.), V Seminario Internacional de Investigación en Urbanismo (pp. 9911009). Barcelona, España: Departament d'Urbanisme i Ordenació del Territori, Universitat Politècnica de Catalunya.

Zuleta J., L. A. \& Jaramillo, L. (2003). Impacto económico del patrimonio del Centro histórico de Bogotá D.C. Bogotá, Colombia: Convenio Andrés Bello. 